British Journal of Nutrition (2022), 127, 1567-1587

doi:10.1017/S0007114521002555

(C) The Author(s), 2021. Published by Cambridge University Press on behalf of The Nutrition Society. This is an Open Access article, distributed under the terms of the Creative Commons Attribution-NonCommercial-NoDerivatives licence (http://creativecommons.org/licenses/by-nc-nd/ 4.0/), which permits non-commercial re-use, distribution, and reproduction in any medium, provided the original work is unaltered and is properly cited. The written permission of Cambridge University Press must be obtained for commercial re-use or in order to create a derivative work.

\title{
Implementation strategies for improving vitamin D status and increasing vitamin D intake in the UK: current controversies and future perspectives: proceedings of the 2 nd Rank Prize Funds Forum on vitamin Dt
}

Judy L. Buttriss ${ }^{1,2}$, Susan A. Lanham-New ${ }^{2 *}$, Simon Steenson ${ }^{1}$, Louis Levy ${ }^{3}$, Gillian E. Swan ${ }^{3}$, Andrea L. Darling ${ }^{2}$, Kevin D. Cashman ${ }^{4}$, Rachel E. Allen ${ }^{5}$, Louise R. Durrant ${ }^{2,6}$, Colin P. Smith ${ }^{7}$, Pamela Magee ${ }^{8}$, Tom R. Hill ${ }^{9}$, Suma Uday ${ }^{10}$, Mairead Kiely ${ }^{4}$, Gael Delamare ${ }^{11}$, Alexa E. Hoyland ${ }^{12}$, Lise Larsen $^{13}$, Laura N. Street ${ }^{14}$, John C. Mathers ${ }^{9}$ and Ann Prentice ${ }^{15}$

${ }^{1}$ British Nutrition Foundation, London, UK

${ }^{2}$ Department of Nutrition, Food and Exercise Sciences, School of Biosciences and Medicine, University of Surrey, Guildford, UK ${ }^{3}$ Public Health England, London, UK

${ }^{4}$ Cork Centre for Vitamin D and Nutrition Research, School of Food and Nutritional Sciences, University College Cork, Cork, Republic of Ireland

${ }^{5}$ Rachel Allen Nutrition, London, UK

${ }^{6}$ Yakult, London, UK

${ }^{7}$ School of Pharmacy and Biomolecular Sciences, University of Brighton, Brighton, UK

${ }^{8}$ Nutrition Innovation Centre for Food \& Health, Ulster University at Coleraine, Coleraine, UK

${ }^{9}$ Human Nutrition Research Centre, Population Health Sciences Institute, Newcastle University, Newcastle-upon-Tyne, UK

${ }^{10}$ University of Birmingham, Birmingham, UK

${ }^{11}$ Campden BRI, Chipping Campden, UK

${ }^{12}$ Kellogg Company, Manchester, UK

${ }^{13}$ Arla Foods Ltd, Aarbus, Denmark

${ }^{14}$ Marks \& Spencer PLC, London, UK

${ }^{15}$ MRC Nutrition and Bone Health Group, University of Cambridge, Cambridge Biomedical Campus, Cambridge, UK

(Submitted 4 November 2020 - Final revision received 22 April 2021 - Accepted 8 June 2021 - First published online 21 July 2021)

Abstract

A multi-disciplinary expert group met to discuss vitamin D deficiency in the UK and strategies for improving population intakes and status. Changes to UK Government advice since the 1st Rank Forum on Vitamin D (2009) were discussed, including rationale for setting a reference nutrient intake $(10 \mu \mathrm{g} / \mathrm{d} ; 400 \mathrm{IU} / \mathrm{d})$ for adults and children (4+ years). Current UK data show inadequate intakes among all age groups and high prevalence of low vitamin D status among specific groups (e.g. pregnant women and adolescent males/females). Evidence of widespread deficiency within some minority ethnic groups, resulting in nutritional rickets (particularly among Black and South Asian infants), raised particular concern. Latest data indicate that UK population vitamin D intakes and status reamain relatively unchanged since Government recommendations changed in 2016. Vitamin D food fortification was discussed as a potential strategy to increase population intakes. Data from dose-response and dietary modelling studies indicate dairy products, bread, hens' eggs and some meats as potential fortification vehicles. Vitamin $\mathrm{D}_{3}$ appears more effective than vitamin $\mathrm{D}_{2}$ for raising serum 25-hydroxyvitamin $\mathrm{D}$ concentration, which has implications for choice of fortificant. Other considerations for successful fortification strategies include: (i) need for 'real-world' cost information for use in modelling work; (ii) supportive food legislation; (iii) improved consumer and health professional understanding of vitamin D's importance; (iv) clinical consequences of inadequate vitamin D status and (v) consistent communication of Government advice across health/social care professions, and via the food industry. These areas urgently require further research to enable universal improvement in vitamin D intakes and status in the UK population.

Key words: Public health: Vitamin $D_{3}$ : Vitamin $D_{2}$ : 25-hydroxyvitamin D: Food fortification

Abbreviations: DNSIYC, Diet and Nutrition Survey of Infants and Young Children; DRV, dietary reference value; 25(OH)D, 25-hydroxyvitamin D; NDNS, National Diet and Nutrition Survey; RCT, randomised controlled trial; RI, reference intake; RNI, reference nutrient intake; SACN, Scientific Advisory Committee on Nutrition.

* Corresponding author: Susan A. Lanham-New, email s.lanham-new@surrey.ac.uk

$\dagger$ The online version of this article has been updated since original publication. A notice detailing the change has been published at https://doi.org/10.1017/ S0007114522000745 
Box 1. Issues highlighted by the COVID-19 pandemic in relation to vitamin D status.

COVID-19 pandemic

This paper has emerged from a Forum on Vitamin D held in September 2019, but finalisation of the manuscript took place during the COVID-19 pandemic.

Of direct relevance to this paper and the proceedings of the Forum, the pandemic has highlighted:

(i) the relatively low vitamin D status of the UK population during late winter when SARS-CoV-2 infection was at its peak;

(ii) the greater burden of COVID-19 morbidity and mortality among people from BAME communities, many of whom have lower than average vitamin D status;

(iii) the urgent need to reinforce UK government recommendations on vitamin $\mathrm{D}$ intakes/supplementation and to implement effective strategies to improve vitamin D status across the UK, in order to maintain musculoskeletal health. This is key as many people have been spending more time indoors than usual during lockdown and so missing out on opportunities for skin synthesis of the vitamin(1);

(iv) a need to determine whether or not vitamin D status influences susceptibility to, and severity of, COVID-19 disease, as discussed by Lanham-New et al. 2020(2). Recent publications concerning vitamin D \& risk of COVID-19(3) and vitamin D \& acute respiratory tract infections(4) emphasise that there is currently insufficient data to confirm a causal link (but both committees will keep a watching brief as new data begins to emerge).

This paper describes the Proceedings of a 2nd Forum on Vitamin D, supported financially by the Rank Prize Funds and held in September 2019 at the University of Surrey, Guildford, UK (3-4 September 2019). Two members of the Rank Prize Funds Nutrition Committee co-chaired workshop sessions. Finalisation of the manuscript took place during the COVID19 pandemic $(\text { Box } 1)^{(1-4)}$. The 1st Forum, held a decade earlier in July $2009^{(5)}$, focused on identification of the concentration of serum 25-hydroxyvitamin D (25(OH)D) (the most widely used and scientifically validated biomarker of vitamin $\mathrm{D}$ status) that might be regarded as optimal for health, whilst recognising the challenges of defining 'optimal'. At that time, the re-emergence of rickets in the UK was already apparent and the public health burden of low vitamin D status globally was well documented. In this context, the 1st Forum on Vitamin D highlighted the need for urgent action from policymakers and risk managers and the failure of UK supplementation policies to achieve the existing vitamin D recommendations ${ }^{(6)}$ for groups designated as 'at-risk' at that time, e.g. infants, ethnic minority groups, pregnant women and older adults

Over the intervening decade, much progress has been made in the vitamin D field. In 2016, the UK's Scientific Advisory Committee on Nutrition (SACN) recommended new vitamin D reference nutrient intakes (RNI) for all age groups. These new vitamin $\mathrm{D}$ recommendations were informed by novel data emerging from dose-response studies in different age groups, new data on the interaction between diet and sunlight exposure on vitamin D status, original data on health effects of vitamin $D$, as well as significant technological advances in the measurement of vitamin D status. In particular, research conducted under the auspices of the EU-funded Vitamin D ODIN project (2013-2017), described later in this paper, made a major contribution, including: further randomised controlled trials (RCT) in underresearched population groups such as pregnant women, women in ethnic minority populations, children and adolescents; and studies using food fortification as an alternative (or complementary approach) to supplementation.

The focus of this 2nd Forum was implementation strategies for improving both vitamin D intake and vitamin D status in the UK. It consisted of a series of presentations on various themes that took place over a period of a day and a half, interspersed with discussion and debate.

The first series of presentations focused on SACN's vitamin D and health evidence review and the resulting recommendations for the UK population ${ }^{(7)}$; current understanding of vitamin D intakes and status in the UK from regional and national surveys; consideration of vitamin D status in 'at-risk' groups, such as ethnic minority groups, pregnant women, children and adolescents; and an overview of UK Government advice on vitamin D supplementation as a means to achieve adequate vitamin D status. The follow-on session considered the evidence from dietary strategies focused on fortification with vitamin $\mathrm{D}_{2}$ and/or vitamin $\mathrm{D}_{3}$.

The third section of the programme took the form of case studies, through a food industry lens, and focused on current practices in food fortification, including consideration of technical issues and consumer attitudes to food fortification.

Throughout the Forum, there were dedicated discussion periods to ensure detailed debate on the specific issues. The event finished with a general discussion that concentrated on the major challenge of risk management. In particular, if it transpires that current public health advice has failed to improve vitamin D status in the UK, what would plan B look like? In other words, what have effective public health strategies targeting vitamin D achieved and what are the characteristics of these effective approaches?

\section{Vitamin D metabolic pathways, recommendations for the UK population, intakes and status}

The first session set the scene with presentations outlining: (1) vitamin D metabolism and the specific deliberations and recommendations on RNIs for vitamin D from the UK's SACN (Prof Ann Prentice, SACN Chair, Medical Research Council and Honorary Professor of Global Nutrition and Health, University of Cambridge); (2) vitamin D intakes and vitamin D status in the UK (Gillian Swan, Public Health England) and (3) the UK Government's response to SACN's recommendations (Prof Louis Levy, Public Health England). An overview of these three presentations follows. 


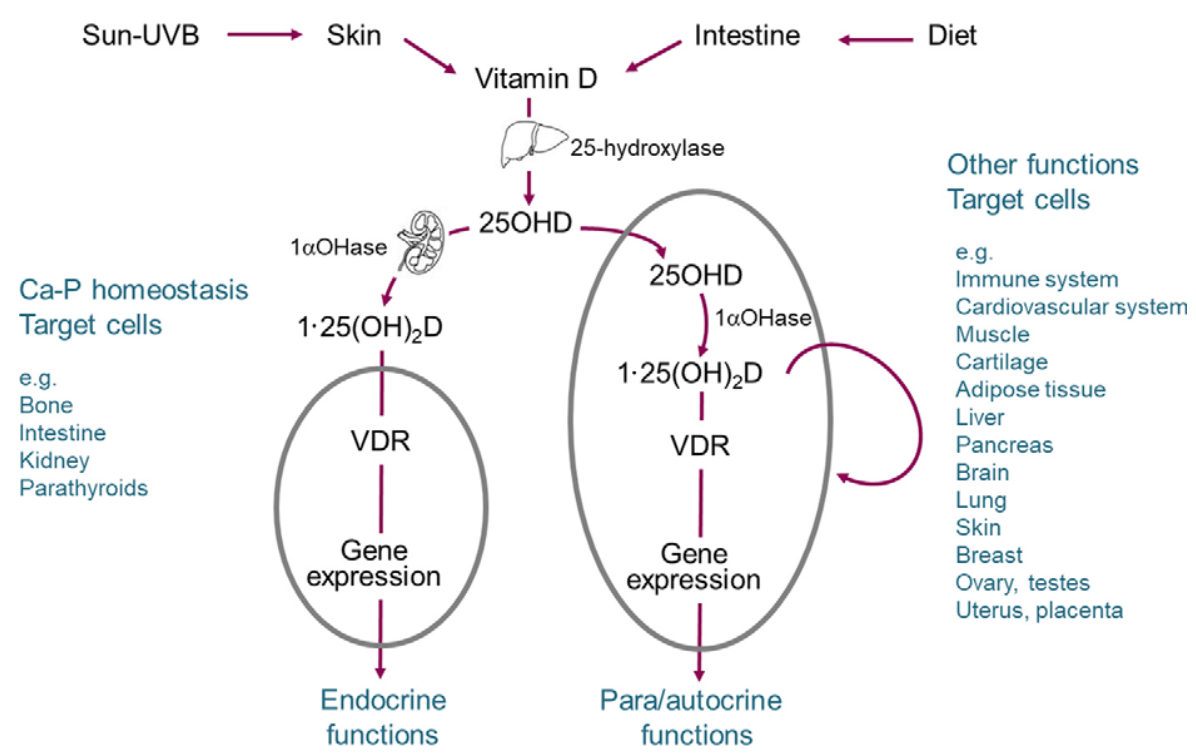

Fig. 1. Vitamin D metabolic pathway. 1,25(OH $)_{2} \mathrm{D}, 1,25$-dihydroxyvitamin $\mathrm{D} ; 1 \alpha \mathrm{OHase}, 1-\alpha$-hydroxylase; VDR, vitamin D receptor. Courtesy of Prof Ann Prentice and modified from Prentice (2007) ${ }^{(10)}$.

Vitamin $\mathrm{D}$ is a generic name for two different secosteroid compounds, ergocalciferol (vitamin $\mathrm{D}_{2}$ ) and cholecalciferol (vitamin $\mathrm{D}_{3}$ ). Vitamin $\mathrm{D}_{3}$ can be obtained from the diet and by endogenous synthesis in the skin via the action of UVB radiation (290-315 nm), which converts 7-dehydrocholesterol to vitamin $\mathrm{D}_{3}$, whereas vitamin $\mathrm{D}_{2}$ is obtained solely from the diet. It is naturally present in fungi (e.g. wild mushrooms or UVB-treated cultivated mushrooms, and yeasts). There are relatively few dietary sources of vitamin $\mathrm{D}_{3}$, the richest being oily fish and egg yolks. Other sources include meat/meat products and fortified foods, such as fat spreads, some breakfast cereals, some dairy products (especially yogurts) and vitamin D-fortified dairy alternatives. In 1940, the fortification of margarine became mandatory in the UK (see DH 1991) ${ }^{(6)}$ but this requirement ceased in $2013^{(8)}$ However, fat spreads (and some other foods) continue to be fortified on a voluntary basis. Infant formula contains vitamin $D$ by law at the level of $1-2.5 \mu \mathrm{g} / 100 \mathrm{kcal}^{(9)}$.

Vitamin D is converted to $25(\mathrm{OH}) \mathrm{D}$ in the liver by the $25-$ hydroxylase enzyme (EC:1.14.14.24) and is the major circulating vitamin D metabolite. In the kidney, 25(OH)D is converted to the active metabolite 1,25-dihydroxyvitamin $\mathrm{D}$, which acts in combination with parathyroid hormone and calcitonin to maintain calcium (Ca) and phosphate homoeostasis (Fig. 1). It should be noted that there is also evidence of extra-renal $1,25(\mathrm{OH}) 2 \mathrm{D}$ synthesis. ${ }^{(11)}$

The most commonly used marker of vitamin D status is $25(\mathrm{OH}) \mathrm{D}$ because it has a relatively long half-life (several weeks) and its concentration in serum/plasma reflects dietary intakes, UVB exposure and biological reserves of vitamin $D$. In the UK, a plasma or serum $25(\mathrm{OH}) \mathrm{D}$ concentration of $25 \mathrm{nmol} / \mathrm{l}$ $(10 \mathrm{ng} / \mathrm{ml})$ is considered to be the 'population protective level' as a minimum for protecting musculoskeletal health and lowering the risk of osteomalacia (adults) and nutritional rickets (children). Characterised by poor bone mineralisation, pain, deformities and fractures, these conditions are caused by low Ca intakes and/or vitamin D deficiency and cured by nutritional intervention. It should be noted that, elsewhere, different thresholds are used; for example, the US Institute of Medicine set a minimum threshold of $30 \mathrm{nmol} / 1$ to define increased risk of deficiency and $50 \mathrm{nmol} / \mathrm{l}$ as the minimum threshold for 'sufficiency $^{\text {(12) }}$, and these thresholds are used in some of the studies mentioned later.

Synthesis of vitamin D following exposure of the skin to UVB radiation is the predominant source for most people in the UK, especially during spring and summer at UK latitudes. During the 'vitamin D winter' period in the UK (ranging from October to February in Southern England and September to April in northern Scotland), ${ }^{(13,14)}$ UVB availability for dermal synthesis of vitamin D is limited or absent. This places increased emphasis on the dietary supply of the vitamin during the 'vitamin D winter'. Some 'at-risk' groups with little or no skin exposure to sunlight during spring and summer, such as those who do not go outside often or who cover most or all of their skin, are reliant on dietary sources of vitamin D throughout the year. Ethnic minority groups with dark skin may not get enough vitamin D from sunlight exposure during the summer months because melanin present in skin limits the rate of skin synthesis ${ }^{(15)}$.

\section{Vitamin D recommendations from Scientific Advisory Committee on Nutrition: deliberations and decisions}

In 1991, the Committee on Medical Aspects of Food and Nutrition Policy set dietary reference values (DRV) for vitamin D for infants (up to 6 months; $8.5 \mu \mathrm{g} / \mathrm{d}$ ), young children (up to 3 years; $7 \mu \mathrm{g} / \mathrm{d}$ ), pregnant and lactating women $(10 \mu \mathrm{g} / \mathrm{d})$, older adults (aged $65+$ years; $10 \mu \mathrm{g} / \mathrm{d}$ ) and those confined indoors or otherwise at-risk of vitamin D deficiency $(10 \mu \mathrm{g} / \mathrm{d})^{(6)}$. However, no DRV for other age groups was considered necessary at that time ${ }^{(6)}$. These DRV were based on providing sufficient vitamin D to protect bone health. In 2010, SACN agreed to review the DRV for vitamin D because a substantial amount of published data had accumulated, including evidence of a high prevalence of low status in additional life stage 
and sex subgroups and new data suggesting a range of other health benefits associated with vitamin $D$.

SACN's comprehensive review of the evidence included: consideration of the association between vitamin $\mathrm{D}$ status and health outcomes at different stages of life and in different population groups; the relative contributions to vitamin D status made by dietary intakes and cutaneous synthesis in the skin; and the potential adverse effects of high vitamin D intakes. The strongest evidence of health benefits for vitamin $\mathrm{D}$ was in the prevention of rickets, osteomalacia and falls, and in benefiting muscle strength and function in adults $\geq 50$ years. Insufficient evidence was found for vitamin $\mathrm{D}$ in relation to non-musculoskeletal outcomes. As a result, musculoskeletal health outcomes were chosen as the basis for setting DRVs. The RNI established for vitamin D was modelled on the basis of maintaining population protective $25(\mathrm{OH}) \mathrm{D}$ concentrations of $\geq 25 \mathrm{nmol} / 1$, at the individual level, throughout the year; below this concentration, the risk of poor musculoskeletal health increases. It was not possible to make any recommendation for the sunlight exposure needed in summertime to ensure winter concentrations remained above $25 \mathrm{nmol} / 1$ due to the large and complex variety of factors that influence UVB skin exposure and because of the potential for skin damage/cancer risk.

Using data from intervention studies, an RNI of $10 \mu \mathrm{g} / \mathrm{d}$ ( 400 $\mathrm{IU} / \mathrm{d}$ ) was established as the amount needed to achieve serum $25(\mathrm{OH})$ D concentrations $\geq 25 \mathrm{nmol} / \mathrm{l}$ during winter in $97.5 \%$ of the population. Although most people would be expected to synthesise vitamin D during summer, between 8 and $53 \%$ of some UK population subgroups have a plasma $25(\mathrm{OH}) \mathrm{D}$ concentration below $25 \mathrm{nmol} / \mathrm{l}$ during the summer months. Therefore, as a precaution, SACN recommended that the RNI is applicable throughout the year to protect the most vulnerable groups in the population and to ensure coverage of $97.5 \%$ of the population. Since no data were available to set an RNI for young children, a 'safe intake' of $8.5-10 \mu \mathrm{g} / \mathrm{d}$ was set for infants from birth until 12 months and $10 \mu \mathrm{g} / \mathrm{d}$ for children aged between 1 and 4 years.

There had been discussion at SACN about possible health concerns for older people with undiagnosed compromised renal function or hyperparathyroidism, who may not be able to excrete or metabolise 25(OH)D sufficiently well to cope with high intakes of supplemental vitamin $\mathrm{D}$, placing them at-risk of hypercalcaemia. Based on the distribution of intakes and $25(\mathrm{OH}) \mathrm{D}$ concentrations in the UK, SACN concluded that with an intake at an RNI of $10 \mu \mathrm{g} / \mathrm{d}(400 \mathrm{IU} / \mathrm{d})$, the upper tail of the distribution was unlikely to approach $25(\mathrm{OH}) \mathrm{D}$ concentrations that might cause concern about toxicity.

In summary, in order to protect those population groups known to be at-risk of a low plasma $25(\mathrm{OH}) \mathrm{D}$ concentration due to minimal skin exposure to sunlight, as well as to protect those unidentified individuals at-risk of low status for any other reason, $\mathrm{SACN}$ recommended that the RNI and safe intake were applicable throughout the year for the whole population. Thus, pregnant and lactating women, and population groups and individuals at-risk of having a 25(OH)D concentration $<25 \mathrm{nmol} / \mathrm{l}$, are included within the recommendation for the general population (Table 1)
Table 1. Reference nutrient intake $(\mathrm{RNI})$ and 'safe intake' values recommended by the Scientific Advisory Committee on Nutrition (SACN 2016)

\begin{tabular}{ll}
\hline Population subgroup & Recommendation* \\
\hline 0 up to 12 months & 'Safe intake' of $8 \cdot 5-10 \mu \mathrm{g} / \mathrm{d}$ \\
1 up to 4 years & 'Safe intake' of $10 \mu \mathrm{g} / \mathrm{d}$ \\
$4-10$ years & $\mathrm{RNI}$ of $10 \mu \mathrm{g} / \mathrm{d}$ \\
$11-18$ years & $\mathrm{RNI}$ of $10 \mu \mathrm{g} / \mathrm{d}$ \\
$19-64$ years & $\mathrm{RNI}$ of $10 \mu \mathrm{g} / \mathrm{d}$ \\
$65+$ years & $\mathrm{RNI}$ of $10 \mu \mathrm{g} / \mathrm{d}$ \\
Pregnant and lactating women & $\mathrm{RNI}$ of $10 \mu \mathrm{g} / \mathrm{d}$ \\
Other 'at-risk' groups & $\mathrm{RNI}$ of $10 \mu \mathrm{g} / \mathrm{d}$ \\
\hline
\end{tabular}

Source: SACN (2016) Vitamin D and health report ${ }^{(7)}$.

* Recommendations from SACN apply to the whole year and are for total intake (diet plus supplements)

† Includes 'at-risk' population subgroups, such as ethnic groups with darker skin and those who do not regularly expose their skin to sunlight during the summer months, who may be at increased risk of having a serum $25(\mathrm{OH})$ D concentration $<25 \mathrm{nmol} / \mathrm{l}$.

\section{Vitamin D intakes and vitamin D status in the UK}

Data for children (aged 1.5 years and older) and adults on vitamin D intakes and plasma 25(OH)D status within the UK population are available from the National Diet and Nutrition Survey (NDNS) ${ }^{(16)}$. The latest NDNS data on vitamin D intakes and status was published in the Years 9 to 11 report (2016/2017 to $2018 / 2019)^{(17)}$ and supersedes the Years 7 and 8 report data $(2014 / 2015 \text { to } 2015 / 2016)^{(16)}$, but was not available at the time the Forum was held. Since the Years 7 and 8 data were those presented and discussed at the Forum, we have included data from these years (see Tables 2 and 3 ).

For children aged 4-18 months, information is provided in the Diet and Nutrition Survey of Infants and Young Children (DNSIYC, 2011) ${ }^{(18)}$. The main dietary contributors for adults and children over 1 year were cereals/cereal products (including fortified breakfast cereals), meat, fish, fortified milk/milk products, eggs and fat spreads, but their relative contributions varied with age (Table 2 ). Fortified milk/milk products were a major contributor for young children, but this food group made a smaller contribution in older children and adults. Conversely, the contribution from meat and fish was higher in adults. The main dietary contributors for infants under 1 year were infant formula and commercial infant foods, meat, fish, eggs, fat spreads and cereals/cereal products (Table 2).

At the time the data in each survey were collected, the only UK RNIs in existence were for infants, pregnant/lactating women, older adults, those confined indoors or otherwise at-risk of vitamin D deficiency ${ }^{(6)}$. With the exception of non-breastfed infants aged 4-12 months in the DNSIYC, mean vitamin D intakes from all sources (food and supplements) were below the RNI subsequently set in 2016 for infants, children and adults of all ages (Table 3). Latest NDNS data (Years 9 to 11; 2016/2017 to $2018 / 2019)^{(17)}$ indicates that total vitamin D intakes (including dietary supplements) and status have not changed substantially since the recommendations were set in 2016. Total vitamin D intakes remained below the RNI for all age/sex groups, except for women aged 65-74 years (mean intake of $10.1 \mu \mathrm{g} / \mathrm{d}$ ). A significant increase in $25(\mathrm{OH}) \mathrm{D}$ status was reported for children aged 4-10 years, compared to Years 7 and 8 of the survey, but changes for other age/sex groups were not significant. 
Table 2. Main contributors (\%) to vitamin D intakes of infants (non-breastfed), children and adults in the UK population* (Percentages)

\begin{tabular}{|c|c|c|c|c|c|c|c|c|c|c|}
\hline & $\begin{array}{c}4-6 \\
\text { months }\end{array}$ & $\begin{array}{c}7-9 \\
\text { months }\end{array}$ & $\begin{array}{c}10-11 \\
\text { months }\end{array}$ & $\begin{array}{c}12-18 \\
\text { months }\end{array}$ & $\begin{array}{l}1.5-3 \\
\text { years }\end{array}$ & $\begin{array}{l}4-10 \\
\text { years }\end{array}$ & $\begin{array}{l}11-18 \\
\text { years }\end{array}$ & $\begin{array}{l}19-64 \\
\text { years }\end{array}$ & $\begin{array}{l}65-74 \\
\text { years }\end{array}$ & $\begin{array}{c}75+ \\
\text { years }\end{array}$ \\
\hline$n$ & 240 & 489 & 381 & 1177 & 250 & 514 & 542 & 1082 & 181 & 154 \\
\hline Cereals and cereal products & 0 & 0 & 1 & 7 & 21 & 30 & 28 & 15 & 12 & 16 \\
\hline of which: Breakfast cereals & 0 & 0 & $\mathrm{~N} / \mathrm{A}$ & $\mathrm{N} / \mathrm{A}$ & 14 & 18 & 18 & 7 & 6 & 8 \\
\hline $\begin{array}{l}\text { Buns, cakes, pastries and } \\
\text { fruit pies }\end{array}$ & 0 & 0 & $\mathrm{~N} / \mathrm{A}$ & $\mathrm{N} / \mathrm{A}$ & 4 & 6 & 4 & 3 & 3 & 5 \\
\hline Milk and milk products & 1 & 3 & 6 & 16 & 25 & 14 & 7 & 5 & 5 & 5 \\
\hline Eggs and egg dishes & 0 & 0 & 2 & 7 & 13 & 12 & 12 & 19 & 20 & 19 \\
\hline Fat spreads & 0 & 1 & 3 & 11 & 12 & 14 & 11 & 11 & 12 & 13 \\
\hline Meat and meat products & 0 & 1 & 3 & 13 & 18 & 21 & 31 & 30 & 23 & 24 \\
\hline Fish and fish dishes & 0 & 1 & 2 & 5 & 7 & 7 & 8 & 17 & 25 & 19 \\
\hline of which oily fish: & 0 & $\mathrm{~N} / \mathrm{A}$ & $N / A$ & $\mathrm{~N} / \mathrm{A}$ & 6 & 5 & 5 & 13 & 21 & 17 \\
\hline Infant formula & 85 & 80 & 72 & 29 & - & - & - & - & - & - \\
\hline $\begin{array}{l}\text { Commercial infant/toddler } \\
\text { foods }\end{array}$ & 12 & 12 & 10 & 9 & $<0.6 \%$ & - & - & - & - & - \\
\hline Other & 2 & 2 & 1 & 3 & 3 & 2 & 3 & 3 & 3 & 4 \\
\hline
\end{tabular}

N/A, data not available.

* Sources: Diet and Nutrition Survey of Infants and Young Children (indicated by shaded cells; DNSIYC, 2011) ${ }^{(18)}$ and the National Diet and Nutrition Survey (years 7 and 8 of the rolling programme; 2014/2015 to 2015/2016) ${ }^{(16)}$. The latest NDNS data on vitamin D intakes and status published in the Years 9 to11 report are now available (December 2020), and supersede the Year 7 and 8 report data in this paper but since the Year 7 and 8 data were presented and discussed at the meeting, we have included these here.

Table 3. Mean vitamin D intakes and vitamin D status of the UK population (including non-breastfed infants*)

\begin{tabular}{|c|c|c|c|c|c|c|c|c|c|}
\hline \multirow[b]{2}{*}{ Age } & \multicolumn{3}{|c|}{ Mean vitamin D intake $(\mu \mathrm{g} / \mathrm{d})^{\dagger}$} & \multicolumn{6}{|c|}{ Mean plasma 25(OH)D $(\mathrm{nmol} / \mathrm{l})$} \\
\hline & Males & Females & Both & Males & $\%$ below $25 \mathrm{nmol} / \mathrm{l}$ & Females & $\%$ below $25 \mathrm{nmol} / \mathrm{l}$ & Both & $\%$ below $25 \mathrm{nmol} / \mathrm{l}$ \\
\hline 4-6 months* & - & - & $10 \cdot 0$ & - & - & - & - & - & - \\
\hline 7-9 months ${ }^{*}$ & - & - & 8.9 & - & - & - & - & - & - \\
\hline 10-11 months* & - & - & $7 \cdot 7$ & - & - & - & - & - & - \\
\hline 12-18 months & - & - & 3.9 & - & - & - & - & - & - \\
\hline 5-11 months & - & - & - & - & - & - & - & 68.6 & 6 \\
\hline $12-18$ months & - & - & - & - & - & - & - & 64.3 & 2 \\
\hline $1.5-3$ years & - & - & $2 \cdot 9$ & - & - & - & - & - & - \\
\hline $4-10$ years & 2.5 & $2 \cdot 8$ & - & $53 \cdot 2$ & 8 & $54.8 \ddagger$ & $13 \ddagger$ & 53.9 & 10 \\
\hline $11-18$ years & 2.5 & 4.6 & - & $45 \cdot 4$ & 15 & 37.9 & 39 & 41.9 & 26 \\
\hline $19-64$ years & 4.5 & 3.9 & - & 44.0 & 19 & $48 \cdot 0$ & 16 & $46 \cdot 1$ & 17 \\
\hline $65+$ years & $5 \cdot 1$ & $6 \cdot 2$ & - & $50 \cdot 0$ & 11 & $51 \cdot 6$ & 15 & 50.8 & 13 \\
\hline
\end{tabular}

Sources: National Diet and Nutrition Survey (years 7 and 8; 2014/2015-2015/2016) and the Diet and Nutrition Survey of Infants and Young Children (indicated by shaded cells; DNSIYC, 2011)(18).

${ }^{*}$ Received no breast milk during the 4-d reporting period.

t Includes contribution from dietary supplements.

$\ddagger$ Sample below $n=50$. The new NDNS data on vitamin D intakes and status published in the Year 9-11 report are now available (December 2020), and supersede the Year 7 and 8 report data in this paper but since the Year $7 \& 8$, data were presented and discussed at the meeting, we have included these.

The population mean concentration of $25(\mathrm{OH}) \mathrm{D}$, averaged across the seasons, measured in these surveys was above the 'population protective level' of $25 \mathrm{nmol} / 1$ in all age groups. The percentage of infants with a plasma $25(\mathrm{OH}) \mathrm{D}$ concentration below $25 \mathrm{nmol} / \mathrm{l}$ was $6 \%$ (infants aged 5-11 months) and $2 \%$ (12-18 months of age). It was noted that sampling for the DNSIYC was weighted towards the summer months when $25(\mathrm{OH}) \mathrm{D}$ concentrations would be expected to be higher ${ }^{(18)}$. In comparison, a greater proportion of children (aged 4 years and over) and adults had plasma $25(\mathrm{OH}) \mathrm{D}$ concentrations below $25 \mathrm{nmol} / \mathrm{l}$ (Table 3 ). In particular, $39 \%$ of girls and $15 \%$ of boys aged 11-18 years were below the threshold, while $19 \%$ of men and $16 \%$ of women (aged 19-64 years) and $11 \%$ of men and $15 \%$ of women (aged $65+$ years) also had a plasma $25(\mathrm{OH}) \mathrm{D}$ below $25 \mathrm{nmol} / \mathrm{l}$ (NDNS results are averages of samples collected across all seasons of the year).
In all age groups, circulating $25(\mathrm{OH}) \mathrm{D}$ concentrations were lowest during the winter months (January to March) and highest during the summer months (July to September). Although recent time trend analysis revealed some statistically significant changes in vitamin $\mathrm{D}$ intakes and status over the past decade (2008-2017), these were small and inconsistent in direction. Vitamin D intake and status increased with income in most age groups $^{(19)}$.

The NDNS shows that a greater proportion of individuals living in Scotland and Northern Ireland had a plasma 25(OH)D concentration below $25 \mathrm{nmol} / 1$ than in the UK as a whole, presumably due to the lower availability of UVB for vitamin D synthesis at more northerly latitudes. In addition, although the NDNS is designed to be a representative sample of the UK, owing to under-representation of participants from ethnic minority groups in the sample, it is not possible to provide specific 
information on the vitamin D intakes and vitamin D status of ethnic minority groups, some of whom may be at greater risk of vitamin D deficiency. However, some recent information, available from other sources, is described later.

In summary, mean intakes during the period 2014-2016, from food and supplements, are below the $2016 \mathrm{RNI}$ in adults and children over 1 year. The main contributors to intake vary a little with age, but in most groups are meat, breakfast cereals, eggs, fat spreads, fortified milk/milk products and oily fish. Infant formula is the highest contributor in young children. While the mean plasma 25(OH)D concentrations measured in 2014-2016 (average of samples collected throughout the year) were above the current RNI in all age groups, a notable proportion had concentrations below $25 \mathrm{nmol} / \mathrm{l}$, for example, $39 \%$ of girls and $15 \%$ of boys aged $11-18$ years and $19 \%$ of men and $16 \%$ of women aged 19-64 years. Intakes and plasma concentrations increase with income, and plasma $25(\mathrm{OH}) \mathrm{D}$ concentrations are highest in the summer and lowest in the winter months.

\section{Policy and public health implications of Scientific Advisory Committee on Nutrition's vitamin D recommendations}

Public Health England's advice, based on SACN's recommendations, can be found in Table 4. Mean intakes of vitamin D from all sources combined (food and supplements) are below the RNI recommended by SACN for most groups of the population. The exception is non-breastfed infants aged 4-9 months consuming infant formula (which contains added vitamin $D$ by law). Data from the Health Survey for England, Scottish Health Survey and cohort studies (as well as data from NDNS, see Table 3) indicate that a notable proportion of some population subgroups in the UK do not achieve a plasma 25(OH)D concentration of $25 \mathrm{nmol} / \mathrm{l}$, even during the summer months. This applies to $17 \%$ of adults living in Scotland; $16 \%$ of adults living in London; $53 \%$ of women of South Asian ethnic origin living in southern England and $29 \%$ of pregnant women in north-west London $^{(7,14)}$.

Professor Louis Levy (Public Health England) explained that, based on the findings of the SACN review, government advice for dietary intakes of vitamin D has been provided as a precautionary measure. This decision was made because of the number and complexity of factors influencing endogenous vitamin D synthesis during the summer months (e.g. limited skin exposure, skin pigmentation), the need to avoid excessive sun exposure (because of skin cancer risk) and the lack of sufficient UVB availability for endogenous synthesis during the winter months. Following SACN's review, several changes to the then existing government advice on vitamin D were announced in July $2016^{(20)}$ (see Table 4). In forming the new public health recommendations, consideration was given to the various factors that may affect vitamin D status, including the seasonality of endogenous vitamin D synthesis at UK latitudes, the frequency of consumption of foods naturally containing, or fortified with, vitamin $\mathrm{D}$, as well as the particular needs of at-risk groups mentioned above. Previous advice ${ }^{(6)}$ about vitamin D supplementation for infants and children was extended to include the period from birth until 6 months, despite some concerns among policymakers that difficulties in using vitamin D drops for younger infants may adversely affect the uptake of advice on breastfeeding. Professor Levy indicated that the need for somewhat complex and nuanced advice (shown in Table 4) appears to have led to an oversimplified interpretation by health and social care professionals, which may be leading to confusion about the detail of the government's recommendations. He also noted that current clinical guidelines from the National Institute for Health and Care Excellence do not reflect the recommendation from SACN that pregnant and breast-feeding women should be considered as a part of the general population (i.e. that vitamin D requirements are the same as for non-pregnant women).

In summary, the current RNIs for vitamin D recommended by SACN relate to the maintenance of plasma (or serum) 25(OH)D concentration to ensure musculoskeletal health. Although the majority of the population achieve the plasma 25(OH)D concentration of $25 \mathrm{nmol} / \mathrm{l}$ during the summer months, as discussed earlier, plasma concentrations are below this in a sizeable proportion of some population subgroups. It is not possible to predict which individuals within subgroups may be at an increased risk of low vitamin $\mathrm{D}$ status owing to the range of factors that determine vitamin status (including dietary intake and skin UVB exposure), and government advice reflects this difficulty.

During the discussion, the pros and cons of vitamin D supplementation versus vitamin D fortification were debated (see Final Discussion). Other points raised were the challenges of delivering advice that is unambiguous and yet appropriately nuanced, an example being how the advice for infants under 1 year to take a supplement ranging from 8.5 to $10 \mu \mathrm{g} / \mathrm{d}$ should be interpreted by parents/carers and supplement manufacturers. Healthy Start vitamin drops provide $10 \mu \mathrm{g}$ vitamin $\mathrm{D}_{3}$ per 5 drops (https:// www.healthystart.nhs.UK/for-health-professionals/vitamins/).

\section{Vitamin D status in ethnic minority groups}

A series of presentations considered vitamin D status in different population subgroups and the prevalence of nutritional rickets. Dr Andrea Darling (University of Surrey) focused on the vitamin D status of ethnic minority groups. The 2006-2007 Diet, Food Intake, Nutrition and Exposure to Sunlight in Southern England (D-FINES) study of South Asian women living in the UK (at a latitude of $52^{\circ} \mathrm{N}$ ) reported that mean $25(\mathrm{OH}) \mathrm{D}$ concentrations remained around the $25 \mathrm{nmol} / 1$ threshold throughout all seasons of the year, with $53 \%$ of women not achieving a concentration $>25 \mathrm{nmol} / \mathrm{l}$ during the summer months ${ }^{(14)}$. Data from the 2010 Health Survey for England have also highlighted that Asian participants (over 16 years) had a lower mean 25(OH)D status $(20.5 \mathrm{nmol} / \mathrm{l})$ than White participants $(45.8 \mathrm{nmol} / \mathrm{l})^{(21)}$.

Dr Darling presented findings from a secondary analysis of data from the UK Biobank cohort (2006-2010) on the determinants of 25(OH)D status for South Asian adults (Indian, Pakistani and Bangladeshi) living in the UK, including information on serum $25(\mathrm{OH}) \mathrm{D}$ concentration as well as vitamin D dietary intakes and supplement use ${ }^{(22,23)}$. The cohort comprises over 500000 people, aged 40-69 years old, among whom are 8024 participants of South Asian ethnicity. Most of the South Asian participants were recruited from Hounslow, 

who were: predominantly of Indian ethnicity (75\%); aged $40-60$ years $(72 \%)$ and living in London (46\%), the north of England (22\%) or the Midlands (20\%). The balance of male (54\%) and female (46\%) participants was approximately even and included individuals with a BMI categorised as underweight/normal weight (32\%), overweight (45\%) and obese (21\%). Blood sampling for each participant was performed during one season only, although data for all four seasons were available across the sub-cohort. Despite the strengths of this large prospective cohort, care should be taken when interpreting results from the UK Biobank because it contains relatively small numbers of some sub-sections of the UK population and because participants are more health conscious than the general population $^{(24)}$.

Regardless of the season when the samples were taken, median serum 25(OH)D concentrations for Indian, Pakistani and Bangladeshi participants were all close to, or below $25 \mathrm{nmol} / \mathrm{l}$, with summer concentrations being only slightly higher than during other seasons ${ }^{(23)}$. During winter and spring, approximately $60 \%$ of participants had a serum 25(OH)D concentration below $25 \mathrm{nmol} / \mathrm{l}$, whilst over $20 \%$ were below $15 \mathrm{nmol} / \mathrm{l}$. Assessing all seasons combined, $92 \%$ of participants had $25(\mathrm{OH}) \mathrm{D}<50 \mathrm{nmol} / \mathrm{l} ; 55 \%$ had $25(\mathrm{OH}) \mathrm{D}<25 \mathrm{nmol} / \mathrm{l}$ and $20 \%$ had $25(\mathrm{OH}) \mathrm{D}<15 \mathrm{nmol} / \mathrm{l}$. Ten percent of participants had missing data as $25(\mathrm{OH}) \mathrm{D}$ was under the detection limit $(10 \mathrm{nmol} / \mathrm{l})$. Logistic regression analysis revealed several factors that predicted a 25(OH)D concentration $<25 \mathrm{nmol} / \mathrm{l}$. These factors included: male sex; Pakistani ethnic origin; higher BMI; being closer to middle age (40-59 years); rarely/never consuming oily fish; vegetarian; little summer sun; not using sun protection (suggesting minimal sun exposure - those who used skin cream presumably spent time in the sun); not using vitamin D-containing supplements and blood sampling during winter/spring. Of note, although $25(\mathrm{OH}) \mathrm{D}$ values were slightly lower for those living at more northerly latitudes, these differences were not statistically significant in the model once adjustment had been made for other confounders. Specifically, the logistic regression model suggested that increased summer sunlight exposure (over $3 \mathrm{~h} / \mathrm{d}$ ), having a normal BMI, eating oily fish twice per week (two servings of fish a week, one being an oily fish, is the current recommendation in the UK) and using supplements reduced risk of vitamin D deficiency.

Previously published work on vitamin D intake and supplement use in the UK Biobank cohort revealed low dietary intakes of vitamin D in Indian (mean of $1.0 \mu \mathrm{g} / \mathrm{d}$ ) and Pakistani (mean of $1.5 \mu \mathrm{g} / \mathrm{d})$ participants. Although Bangladeshi participants had slightly higher intakes $(3.0 \mu \mathrm{g} / \mathrm{d})^{(22)}$, these were far below the RNI of $10 \mu \mathrm{g} / \mathrm{d}$. The majority ( $>60 \%$ ) of south Asian participants of both sexes, and from all three ethnic groups, did not take vitamin D supplements; those who did were, typically, younger, female and living in London ${ }^{(22)}$.

In summary, vitamin D intake is low (1-3 $\mu \mathrm{g} / \mathrm{d})$ and supplement use is also low (only $23 \%$ taking a vitamin D-containing supplement) among UK South Asians. New data suggest that low vitamin D status is almost universal in UK South Asians (e.g. $92 \%<50 \mathrm{nmol} / 1 ; 55 \%<25 \mathrm{nmol} / 1 ; 20 \%<15 \mathrm{nmol} / 1)^{(23)}$. Year round, median serum 25(OH)D concentrations for 
Indian, Pakistani and Bangladeshi participants were all close to, or below, $25 \mathrm{nmol} / \mathrm{l}$, with summer concentrations being only slightly higher than for other seasons. About $10 \%$ had blood vitamin D concentrations below the detection limit $(10 \mathrm{nmol} / \mathrm{l})$. Since the UK Biobank cohort is likely to be more health conscious than the general population ${ }^{(24)}$, vitamin D status in the general South Asian population may be even lower than reported here.

\section{Is vitamin D deficiency prevalent elsewhere in Europe?}

Prof Kevin Cashman (University of Cork, Ireland) summarised the main findings of the 'Food-based solutions for Optimal vitamin D Nutrition and health through the life cycle' (ODIN) project, a large-scale and collaborative 4-year (2013-2017) European Commission FP7-funded project that included a consortium of thirty partners across nineteen countries (Prof Cashman and Prof Kiely, also from the University of Cork, were the project coordinators). The overarching aim of the ODIN project was to develop effective, safe and sustainable foodbased solutions to eradicate vitamin D deficiency and improve health, to benefit all European citizens. The project comprised a total of eleven work packages, including assessing vitamin $D$ requirements, intakes and status, as well as the safety and efficacy of food fortification options ${ }^{(25)}$.

Prior to commencement of the project, no estimate of the prevalence of vitamin D deficiency across Europe had been published. While estimates at a member-state level did exist, these were derived from studies using a range of different analytical methods for serum 25(OH)D. Several reports have shown that available 25(OH)D assays can yield markedly differing results ${ }^{(26)}$. Standardisation of serum $25(\mathrm{OH}) \mathrm{D}$ data, as pioneered as part of the NIH-led Vitamin D Standardization Program ${ }^{(27)}$, offers enormous advantage in reducing method-related differences in 25(OH)D measurement and facilitates better assessment of vitamin $\mathrm{D}$ status within, and between, population studies. The potential for such standardisation of the serum $25(\mathrm{OH}) \mathrm{D}$ measurement was highlighted using samples from the 2011 National Adult and Nutrition Survey for Ireland ( $n$ 1114; aged $18+$ years) and the Vitamin D Standardization Program's standardisation protocol for past surveys. The percentage of Irish adults with serum $25(\mathrm{OH})$ D concentrations $<30 \mathrm{nmol} / 1$ increased from approximately $6 \%$ (as assessed by original immunoassay) to approximately $12 \%$ of participants when samples were standardised by the Vitamin D Standardization Program protocol ${ }^{(28)}$. ODIN applied the Vitamin D Standardization Program protocols to existing serum 25(OH)D data from approximately 56000 individuals from eighteen nationally and regionally representative populations across Europe and provided the first European-wide estimate of vitamin D deficiency prevalence $^{(29)}$. Approximately one in eight Europeans had a $25(\mathrm{OH}) \mathrm{D}$ concentration $<30 \mathrm{nmol} / \mathrm{l}$, and $40 \%$ were below 50 $\mathrm{nmol} / \mathrm{l}$. The prevalence of $25(\mathrm{OH}) \mathrm{D}<30 \mathrm{nmol} / \mathrm{l}$ was considerably higher among darker-skinned ethnic minority groups than for White Europeans in the UK (Black 36\%; Asian $60 \%$; White about $20 \%$ ), Norway (South Asian 65\%; White about 1\%) and Finland (Somali $28 \%$; Kurdish $50 \%$; White 0.5\%).

There is no single underlying reason for vitamin D deficiency, but the combination of low UVB availability and/or exposure coupled with a low dietary vitamin D intake are of key importance ${ }^{(30)}$. Sufficient UVB radiation for endogenous vitamin $\mathrm{D}$ synthesis is available during the summer months throughout Europe, but this is not the case in most European countries during the winter ${ }^{(31)}$. The number of months during which synthesis of vitamin D in the skin is not possible ('vitamin $\mathrm{D}$ winter') increases with latitude, from 0 to 2 months in southern Europe (Greece), 5 to 6 months in the UK and Ireland, to 7 or more months in the most northerly countries (Norway and Iceland). In the absence of sufficient UVB availability/exposure to enable synthesis in the skin, dietary supply of vitamin $\mathrm{D}$ is critical to meeting population requirements and prevention of vitamin D deficiency. An analysis of surveys conducted throughout Europe ${ }^{(32)}$ showed that approximately $50 \%-100 \%$ of adults have inadequate dietary intakes of vitamin $\mathrm{D}$, i.e. below $10 \mu \mathrm{g} / \mathrm{d}$, with higher prevalence in older adults.

\section{Child and maternal vitamin $\mathrm{D}$ requirements}

Professor Mairead Kiely reiterated that SACN recommendations are for healthy members of the general population, which includes pregnant women, who are usually under medical supervision. Within the neonatal period (the month following birth), babies are under observation either by their health visitor and/or the primary care team and postnatal staff. After this time, babies and children are considered part of the 'general population'. As noted above, the current UK government recommendations for vitamin D include a safe intake value of $8 \cdot 5-10 \mu \mathrm{g} / \mathrm{d}$ throughout the first year of life and $10 \mu \mathrm{g} / \mathrm{d}$ throughout the year for ages $1-4$ years (see Table 4). The RNI of $10 \mu \mathrm{g} / \mathrm{d}$ (400 IU/d) for pregnant and lactating women is the same as for nonpregnant adults.

\section{Infants}

In a well-conducted dose-response RCT of vitamin D among infants aged 1 month, who were followed to 12 months of age, Gallo et al. (2013) ${ }^{(33)}$ reported that $10 \mu \mathrm{g} / \mathrm{d}$ of vitamin $\mathrm{D}_{3}$ maintained $25(\mathrm{OH}) \mathrm{D}$ concentrations $>50 \mathrm{nmol} / \mathrm{l}$ for $97 \%$ of infants, with no advantages for vitamin $\mathrm{D}$ status or bone mineral density of higher doses $(20,30$ and $40 \mu \mathrm{g} / \mathrm{d})$. Indeed, the $40 \mu \mathrm{g} / \mathrm{d}$ dose increased the risk of hypercalcaemia and was subsequently discontinued during the trial. Following this study, there has been broad agreement between regulatory authorities, around the world, that recommendations for vitamin D during infancy should be about $10 \mu \mathrm{g} / \mathrm{d}$.

\section{Young children}

Dose-response RCTs in young children are still required to estimate evidence-based RNIs for this age group, as well as to underpin the upper intake level estimates. These are currently applied on the basis of body weight estimates rather than experimental data. Observational data from a prospective birth cohort study conducted in Cork $\left(51^{\circ} \mathrm{N}\right)$ among 741 two-year-olds showed a low $(<2 \%)$ prevalence of $25(\mathrm{OH}) \mathrm{D}$ concentrations below $25 \mathrm{nmol} / \mathrm{l}$, despite average vitamin D intakes of $3.5 \mu \mathrm{g} / \mathrm{d}$, with $96 \%$ below $10 \mu \mathrm{g} / \mathrm{d}^{(34)}$. This report is in line with other 
observational studies in Canada showing healthy circulating concentrations of $25(\mathrm{OH}) \mathrm{D}$ among children, even during winter, despite lower vitamin $\mathrm{D}$ intakes than recommended ${ }^{(35)}$. It is possible that the dietary requirement in this age group could be slightly lower than in older children and adults due to smaller body size and a consequently higher dose-response; further research is urgently required.

Besides season of sampling, vitamin D intake was the only other significant determinant of serum $25(\mathrm{OH}) \mathrm{D}$ in the Cork cohort. The highest prevalence of serum $25(\mathrm{OH}) \mathrm{D}<30$ $\mathrm{nmol} / \mathrm{l}$, particularly in winter, was among children who neither used a vitamin D-containing supplement nor consumed vitamin D-fortified food. Among these specific individuals, the mean intake of vitamin $D$ was just over $1 \mu \mathrm{g} / \mathrm{d}^{(34)}$.

\section{School-age children and teenagers}

As part of the ODIN project, a dose-response RCT was carried out in Denmark among 4-8-year-old white-skinned boys and girls ${ }^{(36)}$. The intakes of vitamin $\mathrm{D}_{3}$ required to maintain $25(\mathrm{OH}) \mathrm{D}$ above 25 and $50 \mathrm{nmol} / \mathrm{l}$ in $97.5 \%$ of children were $6.4 \mu \mathrm{g} / \mathrm{d}$ and $19.5 \mu \mathrm{g} / \mathrm{d}$, respectively. In Sweden, a separate trial among white- and darkskinned children aged 5-7 years reported that while $6 \mu \mathrm{g} / \mathrm{d}$ was sufficient for white-skinned children to achieve $30 \mathrm{nmol} 25(\mathrm{OH})$ $\mathrm{D} / 1,14 \mu \mathrm{g} / \mathrm{d}$ was required to meet this threshold in darker-skinned children $^{(37)}$. The equivalent intakes to achieve $50 \mathrm{nmol} / 1$ were about 20 and $28 \mu \mathrm{g} / \mathrm{d}$ for white- and darker-skinned children, respectively. These data reinforce data from adults highlighting the strong possibility of different dose-responses between ethnic groups, with higher vitamin $\mathrm{D}$ requirements for individuals in BAME (Black, Asian and minority ethnic) groups. Adding to limited data for teenagers, Smith et al. (2016) ${ }^{(38)}$ reported outcomes from an ODIN dose-response RCT carried out in Southern England which showed that $10 \cdot 1 \mu \mathrm{g} / \mathrm{d}$ of vitamin $\mathrm{D}_{3}$ was required to keep $97.5 \%$ above $25 \mathrm{nmol} / 1$ during wintertime, a value consistent with earlier data from adults ${ }^{(39,40)}$ and with SACN's conclusions $(2016)^{(7)}$. During the discussion, it was noted that the outcomes from the ODIN studies in young children, as well as other studies from Sweden and Canada, were published after 2016.

\section{Pregnant women}

It is not known whether dietary recommendations for adults in general are appropriate for pregnant women. To address this issue, further research is urgently required to provide answers to several questions including: (i) is the prevalence of low vitamin D status greater among pregnant women than among nonpregnant women; (ii) does altered vitamin D metabolism in pregnancy increase vitamin D requirements; (iii) is there evidence for adverse perinatal effects of low vitamin D status during pregnancy that justifies additional vitamin $\mathrm{D}$ to support healthy pregnancy and, if not, what is the appropriate basis on which a healthy range for $25(\mathrm{OH}) \mathrm{D}$ blood concentrations in pregnancy should be framed? ${ }^{(41)}$

There is evidence for a higher prevalence of low vitamin D status during pregnancy than among non-pregnant adults ${ }^{(42)}$, the burden of which is borne disproportionately by women from ethnic minority groups. Multiple systematic reviews of the role of vitamin D and vitamin D supplementation during pregnancy have been published ${ }^{(43-45)}$, but, as yet, there is no consensus as to whether the physiological requirements for $25(\mathrm{OH}) \mathrm{D}$ are greater during pregnancy than in non-pregnant women. Professor Kiely suggested that this question has been framed around the benefit of vitamin D supplementation rather than the role of sufficient vitamin D status to support a healthy pregnancy. At birth, an infant's vitamin D status is completely dependent on maternal status and low vitamin D status among new born infants is common ${ }^{(42)}$. For example, in Ireland, $35 \%$ of more than 1000 umbilical cord serum samples had 25(OH)D concentrations below $25 \mathrm{nmol} / \mathrm{l}^{(46)}$. Based on the hypothesis that umbilical cord 25(OH)D concentrations reflect fetal vitamin D status, prevention of infantile 25(OH)D falling below $25 \mathrm{nmol} / \mathrm{l}$ (reflected in umbilical cord sera) has been proposed as a potential target for protection of the fetal/infant skeleton ${ }^{(41,47)}$.

O'Callaghan et al. (2018) ${ }^{(48)}$ reported the first dose-response study in pregnant women to address the question of how much vitamin $\mathrm{D}$ would prevent cord $25(\mathrm{OH}) \mathrm{D}$ concentration falling below $25 \mathrm{nmol} / \mathrm{l}$. When maternal 25(OH)D concentrations were $\geq 50 \mathrm{nmol} / 1$ during the third trimester, cord sera were $>25$ $\mathrm{nmol} / \mathrm{l}$ at delivery. The vitamin $\mathrm{D}_{3}$ intake required to maintain maternal 25(OH)D above $50 \mathrm{nmol} / \mathrm{l}$ among $97.5 \%$ of mothers was $30 \mu \mathrm{g} / \mathrm{d}$.

In summary, high-quality data from dose-response RCTs are available to inform RNIs for vitamin D intakes among infants, children and teenagers. However, RCT data for pre-school children are still required, from risk and safety perspectives, as well as for BAME populations. Data from a high-quality doseresponse RCT show that white-skinned pregnant women require $30 \mu \mathrm{g} / \mathrm{d}$ vitamin $\mathrm{D}_{3}$ to maintain 25(OH)D above $50 \mathrm{nmol} / \mathrm{l}$ and thus prevent new born $25(\mathrm{OH}) \mathrm{D}$ concentrations falling below $25 \mathrm{nmol} / \mathrm{l}$. Replication of dose-response RCTs is required in pregnant women from ethnic minority groups.

\section{Nutritional rickets in the UK}

Dr Suma Uday (University of Birmingham, UK) discussed the burden of rickets in the UK, contrasted UK vitamin D supplementation policy with other European countries and made suggestions for improving adherence to supplementation, particularly in infants. Nutritional rickets and hypocalcaemic complications related to severe vitamin D deficiency are more common among BAME groups residing in the UK than among White children. Dr Uday discussed three clinical cases, from a single UK tertiary centre, of infants (aged 5-6 months) with darker skin who presented in early spring with cardiac arrest, respiratory arrest following seizure or severe respiratory distress ${ }^{(49)}$. All three infants were noted to have severe hypocalcaemia (adjusted Ca 1.2-1.96 mmol/ 1; normal range $2 \cdot 2-2 \cdot 7 \mathrm{mmol} / \mathrm{l})$ with elevated alkaline phosphatase (802-1123 $\mu \mathrm{g} / \mathrm{l}$; normal range 105-357 $\mu \mathrm{g} / \mathrm{l})$ and parathyroid hormone levels (219-482 ng/l; normal range 13-29 ng/l) and very low serum 25(OH)D concentrations $(<15 \mathrm{nmol} / \mathrm{l})$. Severe underlying rickets on radiographs and dilated cardiomyopathy (enlargement of the heart) were uncovered on further investigation. It was highlighted that none of the infants was on vitamin D supplements and the need for supplements had not been raised during child 
surveillance visits in any of the cases. One infant sadly died from cardiac arrest. Post-mortem examination revealed florid rickets with: rachitic rosary ('beading' of the ribs), abnormally widened rib growth plate on histology (widened, irregular zone of hypertrophic chondrocytes), increased osteoid thickness and volume and extremely low bone mineralisation on histomorphometry ${ }^{(49)}$.

The incidence of hospital admissions due to rickets in England increased between 2000 and $2011^{(50)}$. A survey conducted by the British Paediatric Surveillance Unit between March 2015 and March 2017 suggested an annual overall incidence of 0.48 cases per 100000 (sixty cases per year) of nutritional rickets, with the greatest number of cases in infants aged 12-23 months, and of BAME origin ${ }^{(51)}$. The limitations of the survey included a strict case definition leading to exclusion of a significant number of cases, including those of hypocalcaemic seizures ${ }^{(52)}$. The nature of the survey also meant that it did not capture cases seen in primary care or those seen by general practitioners who are not adequately trained in paediatrics. Nonetheless, it is important to note that nearly $80 \%$ of the cases in the survey were not taking the recommended vitamin D supplements. Four cases of dilated cardiomyopathy were identified, of whom two sadly died, highlighting the associated morbidity and mortality. Moreover, nutritional rickets cases presenting to secondary care are only the tip of the iceberg of hidden widespread vitamin D deficiency ${ }^{(50)}$. Depending on the study design and case definition, the incidence of rickets (per 100000 people) among darker skinned and immigrant populations in the UK (95/ 100 000), USA (220/100 000), Australia (2300/100 000) and Denmark (60/100 000) have all been reported to exceed the incidence rate for classification as a rare disease $(50 / 100000)^{(53)}$. In the UK, in addition to the increasing proportion of BAME residents ( $14 \%$ in the 2011 census), there is a yearly net positive migration of approximately 150-200 000 BAME individuals ${ }^{(54)}$. Hence, the disease burden is likely to rise unless effective strategies for prevention are implemented.

An evidence-based global consensus statement on recommendations for the prevention and management of nutritional rickets was published in $2016^{(47)}$. A group of thirty-three experts, from various fields, developed definitions for sufficiency, insufficiency and deficiency of serum 25(OH)D and daily Ca intakes for the prevention and management of nutritional rickets (Table 5). Universal supplementation of $400 \mathrm{IU} / \mathrm{d}(10 \mu \mathrm{g} / \mathrm{d})$ was recommended by the Global Consensus Group for infants (birth to 12 months), a $600 \mathrm{IU} / \mathrm{d}(15 \mu \mathrm{g} / \mathrm{d})$ supplement for pregnant women and lifelong supplementation of $600 \mathrm{IU} / \mathrm{d}(15 \mu \mathrm{g} / \mathrm{d})$ for those considered to be at-risk, in addition to ensuring adequate Ca intakes. A recent survey (based on questionnaire responses from expert representative members of the Bone and Growth Plate Working group of the European Society of Paediatric Endocrinology) identified that the UK has the lowest adherence (5-20\%) in Europe to infant vitamin D supplementation advice, based on data from twenty-nine countries ${ }^{(55)}$. Factors that were statistically significantly linked to increased adherence in other countries were universal supplementation of breast- and formula-fed infants $(P=0 \cdot 007)$, monitoring of adherence at child health surveillance visits $(P=0 \cdot 001)$, giving information to parents at discharge from neonatal units $(P=0 \cdot 02)$ and providing financial family support $(P=0 \cdot 005)$.
Table 5. Global Consensus Group recommendations for the prevention and management of nutritional rickets in infants, children and adolescents $^{(47)}$

\begin{tabular}{lll}
\hline Classification & Serum 25-hydroxyvitamin D & Dietary Ca intake* \\
\hline Sufficiency & $>50 \mathrm{nmol} / \mathrm{l}$ & $>500 \mathrm{mg} / \mathrm{d}$ \\
Insufficiency & $30-50 \mathrm{nmol} / \mathrm{l}$ & $300-500 \mathrm{mg} / \mathrm{d}$ \\
Deficiency & $<30 \mathrm{nmol} / \mathrm{l}$ & $<300 \mathrm{mg} / \mathrm{d}$ \\
\hline
\end{tabular}

* Recommendations for children over 12 months of age. For infants $0-6$ and 6-12 months of age, the adequate $\mathrm{Ca}$ intake recommended is 200 and $260 \mathrm{mg} / \mathrm{d}$, respectively. For children over 12 months of age, a dietary $\mathrm{Ca}$ intake of $<300 \mathrm{mg} / \mathrm{d}$ increases the risk of rickets independently of serum 25-hydroxyvitamin D concentration.

Dr Uday argued that the adherence to supplementation advice in the UK could be improved by a combination of some of the above strategies. Universal supplementation of breast- and formula-fed infants would give a simple message to professionals and also the public. There is evidence from the recent British Paediatric Surveillance Unit survey ${ }^{(51)}$ and a previous hypocalcaemic seizure survey ${ }^{(56)}$ that formula-fed infants can be affected by rickets and that fortified formula alone does not guarantee protection against nutritional rickets ${ }^{(57)}$. Mandatory monitoring of adherence to supplements at child health surveillance visits will prompt healthcare professionals to check and recommend supplements. Dr Uday suggested that there are simple practical monitoring approaches that could be used.

In summary, the potentially devastating health consequences of vitamin D deficiency in infancy are preventable, yet it is evident that the UK government's advice on vitamin D supplementation in infancy is not reaching all families. Whilst the government has supplementation policies in place, there is a lack of implementation strategies. Given the significant mortality and morbidity associated with this preventable condition, Dr Uday suggested that the government should consider robust strategies for an infant vitamin D supplementation programme similar to those used in immunisation programmes. In concluding, Dr Uday recommended: (i) universal supplementation and simplified advice; (ii) increased monitoring of adherence to supplementation advice; (iii) financial support or incentives for general practitioners to implement infant vitamin D supplementation and (iv) information at birth and antenatal visits.

Subsequent discussion focused on strategies to improve awareness at 'grassroots' level about the clinical significance and long-lasting consequences of inadequate vitamin D intakes. Available evidence suggests that families are unaware of the UK government's advice, rather than rejecting it, which emphasises the importance of health professionals being aware of the potentially serious consequences of vitamin D deficiency, the population subgroups considered to be at particular risk, and routinely alerting parents and carers to the need for supplementation. Subtle inconsistencies in the communication of the government's advice, as reflected in the wording of guidelines from several expert bodies, may be leading to confusion among general practitioners and healthcare professionals.

It was suggested that a national publicity campaign might be useful for raising public awareness. However, experience to date suggests that to be effective, this approach needs to be reinforced by other actions. In particular, accurate and consistent messages (in line with government advice) delivered by 
healthcare professionals in routine contact with parents may be more effective in this case. Reinforcement of government advice through local community groups and initiatives, such as faith and parenting groups, may be particularly helpful in reaching at-risk groups of the population.

\section{Food-based solutions for enhancing vitamin D status}

Three potential strategies for addressing poor micronutrient intakes have been identified by the WHO and the FAO of the UN, i.e. increasing the diversity of foods consumed; food fortification and nutrient supplementation ${ }^{(58)}$; all of which may be relevant to addressing the widespread prevalence of inadequate vitamin D intake.

While often discussed as a possible means of closing the gap between current vitamin D intakes and vitamin D recommendations, increasing supplement usage as an appropriate public health strategy to increase intakes across the population has intrinsic limitations. This is because vitamin D supplements are only effective in those who consume them, and their usage can be low, for example, $<20 \%$ use of vitamin D-containing supplements in Ireland and the UK. Novel approaches to supplementation are being developed, such as vitamin D sprays for oral use (discussed further below) ${ }^{(59,60)}$.

As a means of addressing low vitamin D intakes, increasing the diversity of foods consumed is particularly challenging because there are very few food sources naturally rich in vitamin $\mathrm{D}$, and these are predominantly of animal origin. This is especially relevant in the context of the recent calls for a radical transformation of the global food system - with specific emphasis on increased consumption of plant-based foods and reductions in animal-derived foods for many, as part of a more sustainable flexitarian-type $\operatorname{diet}^{(61)}$. The WHO/FAO have indicated that food fortification has potentially the widest and most sustainable impact and is generally considered more cost-effective than other intervention approaches ${ }^{(58)}$ (WHO/FAO, 2006). The potential importance of food fortification (and biofortification) as a means of improving vitamin D status at a population level was emphasised during the Forum discussions. A populationlevel approach was emphasised during this Forum and has been discussed previously, ${ }^{(62)}$ with Finland leading the way with vitamin D food fortification strategies.

Prof Kevin Cashman from University College Cork (Ireland) explained that a number of RCTs conducted during the winter months, as part of the ODIN project, found that several fortified foods were effective at preventing serum $25(\mathrm{OH}) \mathrm{D}$ concentrations below $30 \mathrm{nmol} / \mathrm{l}$ in the treatment group (i.e. zero or very low prevalence). These fortified foods included UV-exposed mushrooms (providing around $100 \mu \mathrm{g} \mathrm{D} / \mathrm{d}$ ) ${ }^{(63)}$, eggs biofortified with vitamin $\mathrm{D}_{3}$ and $25(\mathrm{OH}) \mathrm{D}_{3}(4-5 \mu \mathrm{g} \text { per egg })^{(64)}$ and fortified low-fat Gouda cheese (about $6 \mu \mathrm{g} \mathrm{D} / \mathrm{d}$ ) ${ }^{(65)}$. The only fortification approach studied that was not found to be effective was the use of UV-irradiated yeast (about $25 \mu \mathrm{g} / \mathrm{d}$ ), containing vitamin $D_{2}$, used specifically to make bread, which did not raise total $25(\mathrm{OH}) \mathrm{D}$ concentrations, presumably due to lower bioavailability ${ }^{(66)}$. However, fortification of bread with vitamin $D_{3}$ has been shown to be effective in enhancing vitamin D status ${ }^{(67)}$. Overall, fortification of foods with vitamin $\mathrm{D}$ was deemed to be technologically feasible, and sensory data indicated a good level of consumer acceptability ${ }^{(64)}$.

A dietary modelling analysis has been performed to explore the potential effect of the fortified foods tested within ODIN on raising total vitamin D intakes within several EU countries. For example, data from the National Adult and Nutrition Survey for Ireland were modelled as follows: the contribution from supplements and existing fortified foods was removed to create a 'baseline' intake value. When current intakes of individual products were replaced in the modelling by a combination of biofortified foods (beef, pork and eggs), as well as fortified milk and cheese, baseline intakes were estimated to increase from $3 \cdot 3 \mu \mathrm{g} / \mathrm{d}$ to $8 \cdot 0$ $\mu \mathrm{g} / \mathrm{d}$, thus almost achieving the target intake of $10 \mu \mathrm{g} / \mathrm{d}$. An integrated predictive model, which accounted for changes in UVB availability during the year, suggested that the prevalence of a $25(\mathrm{OH}) \mathrm{D}$ concentration $<30 \mathrm{nmol} / \mathrm{l}$ during winter in Irish adults (18.1\%) could be reduced to $6.6 \%$ by the stepwise introduction of an increasing number of fortified foods ${ }^{(68)}$. In relation to the efficacy of fortification for at-risk ethnic minority groups, a recent 12 week RCT among women of Pakistani origin, conducted in Denmark, reported that vitamin D-fortified foods, together providing an intake of $20 \mu \mathrm{g} / \mathrm{d}$, reduced the prevalence of $25(\mathrm{OH}) \mathrm{D}<30$ $\mathrm{nmol} / \mathrm{l}$ from $34 \%$ to $3 \%{ }^{(69)}$.

In the ODIN modelling, consideration was also given to whether consumption of fortified foods could increase the risk of exceeding the upper intake level for vitamin D of $100 \mu \mathrm{g} / \mathrm{d}$ ( $4000 \mathrm{IU} / \mathrm{d}$ ) (adults). Consumption of a combination of fortified and biofortified foods did not pose a risk at the 99th percentile of the distribution. Even those taking high dose supplements (50 $\mu \mathrm{g} / \mathrm{d}$ ) in addition to fortified foods would be unlikely to reach the upper intake level. In summertime, endogenous vitamin D synthesis in individuals with plentiful sun exposure is self-regulating; thus, when combined with fortified foods, this would not be expected to lead to excessive exposure to vitamin D. However, this assumption needs to be tested.

Professor Cashman emphasised that while the RCT evidence suggests a benefit from fortification, one of the greatest challenges is how to take interventions shown to work in a research setting and implement them in a real-world setting; a key issue highlighted by $\mathrm{WHO}^{(70)}$. The success of a voluntary, government-driven vitamin D fortification policy in Finland was given as an example. Following introduction of the policy in 2003 , the percentage of the population with a $25(\mathrm{OH}) \mathrm{D}$ concentration $<30 \mathrm{nmol} / 1$ decreased from $12 \%$ in 2000 to $<1 \%$ in $2011^{(71)}$. Also of note, the introduction of vitamin $\mathrm{D}$ food fortification resulting in a much higher increase (about $34 \mathrm{nmol} / \mathrm{l}$ ) in those with vitamin $\mathrm{D}$ deficiency $(<30 \mathrm{nmol} / \mathrm{l})$ and the least (about $11 \mathrm{nmol} / \mathrm{l})$ in participants with adequate (>50 nmol/l) serum $25(\mathrm{OH}) \mathrm{D}$ concentration at baseline ${ }^{(71)}$

In summary, low 25(OH)D concentrations (below $30 \mathrm{nmol} / \mathrm{l}$ ) remain relatively common in Europe and there is a several-fold higher risk among a number of ethnic minority groups. Animalfeeding trials, food production studies and food-based RCTs, accompanied by dietary modelling experiments, have demonstrated that diverse fortification strategies could increase vitamin $\mathrm{D}$ intake across the distribution of population intakes and thus reduce the risk of deficiency. There is an urgent need for 
follow-up research and implementation per se to scale up interventions into real-world settings, with the ultimate aim of preventing vitamin $\mathrm{D}$ deficiency.

\section{Use of hens' eggs as a food fortification vehicle}

Professor Tom Hill (Newcastle University) highlighted the re-emergence of the popularity of eggs in the UK in recent years and their potential as a vehicle for vitamin D fortification. Egg yolk is one of the few naturally occurring sources of vitamin D. Biofortification of hens' eggs, through the addition of vitamin $\mathrm{D}_{3}$ and/or $25(\mathrm{OH}) \mathrm{D}_{3}$ to feed, increases the total vitamin D content of eggs in a dose-dependent manner ${ }^{(72)}$. This is in addition to providing benefits to the producer in terms of bird health, welfare and productivity. Although $25(\mathrm{OH}) \mathrm{D}_{3}$ is a relatively expensive feed ingredient in egg production, its use as a biofortificant has been shown to be up to five times more efficient than vitamin $\mathrm{D}_{3}$ in raising serum $25(\mathrm{OH}) \mathrm{D}$ concentration during wintertime in older adults ${ }^{(73)}$. Eggs enriched with vitamin $\mathrm{D}_{3}$ or $25(\mathrm{OH}) \mathrm{D}_{3}$ maintained wintertime $25(\mathrm{OH}) \mathrm{D}$ concentrations in $\operatorname{adults}^{(64)}$.

The commercial potential for fortification of eggs was explored in an Innovate UK-funded project ('Sunshine Egg: a novel and healthier vitamin D enriched food'), which was a collaboration between Newcastle University, DSM and Noble Foods (see https://gtr.ukri.org/projects?ref=131899 for further details). The degree of change in vitamin $\mathrm{D}$ content of eggs from both colony and free-range hens was assessed after a 6-week period of feed supplementation with vitamin D. Three different feed supplementation protocols were tested: (1) low vitamin D (3000 IU ( $75 \mu \mathrm{g}$ ) vitamin $\mathrm{D}_{3}$ per $\mathrm{kg}$ ); (2) medium (a combination of $1500 \mathrm{IU}(37.5 \mu \mathrm{g})$ vitamin $\mathrm{D}_{3}$ and $37.5 \mu \mathrm{g} 25(\mathrm{OH}) \mathrm{D}_{3}$ per $\left.\mathrm{kg}\right)$ and (3) high $\left(75 \mu \mathrm{g} 25(\mathrm{OH}) \mathrm{D}_{3}\right.$ per $\left.\mathrm{kg}\right)$. All three protocols were below the maximum permissible levels set by the European Food Safety Authority (EFSA). Thirty eggs from each of ten flocks of hens (flocks varied in size between 9000 and 123200 hens) were tested at 0,3 and 6 weeks. The total vitamin D content of eggs was $43 \%$ higher in eggs from hens given feed with the highest vitamin D content, with no significant increase compared with baseline for the low and medium treatment groups. The percentage improvement in vitamin $\mathrm{D}$ content from week 0 to week 3 (22\%) and week 0 to week 6 (43\%) suggests a linear increase in vitamin D content over 6 weeks. No differences in egg shell strength or the incidence of hen mortality were found.

The success of the intervention has led to adoption of the research findings and a re-launch of Noble Foods' brand (The Happy Egg Co.), which now features a nutrition claim $(28 \%$ more vitamin D than standard eggs). The brand has an annualised retail value of $£ 71.5 \mathrm{~m}$ and is purchased by 5.9 million UK households. Enrichment of eggs with vitamin D was not associated with any additional cost to the consumer. Further work, funded by Innovate UK, will investigate strategies to overcome barriers to achieving the commercial potential of vitamin D enrichment of eggs. The project aims to address knowledge gaps such as the effects of egg storage, processing and cooking on vitamin D content, as well as effects on vitamin D status of human participants consuming the eggs, consumer acceptability and market opportunities (see https://gtr.ukri.org/projects?ref= 133606 for further details). The consortium also hopes to explore the potential for more widespread vitamin D enrichment of eggs with the British Egg Industry Council and other egg producers via the Lion code of practice.

In the discussion, it was noted that, although hens can synthesise vitamin D in response to exposure of their legs to UVB light, this is not easy to do commercially, and so hens are reliant on a dietary supply. The advantages of the use of vitamin D-enriched eggs in situations such as care homes for elderly people were mentioned.

In summary, eggs are a valuable dietary source of vitamin D and other nutrients and there is scope to enhance the vitamin D content of eggs by supplementing the feed of hens. A vitamin D concentration in enriched eggs of up to $4 \mu \mathrm{g}$ per egg should be possible commercially, although further work is needed (according to McCance and Widdowson's food tables ${ }^{(74)}$ current average vitamin $\mathrm{D}$ content of a composite of barn, free range and organic eggs is $1.7 \mu \mathrm{g}$ for a $50 \mathrm{~g}$ egg and $2.1 \mu \mathrm{g}$ for a $60 \mathrm{~g} \mathrm{egg}$ ). Understanding how to most effectively communicate the benefits of egg fortification with vitamin D will be critical if the full potential of egg enrichment is to be realised.

\section{Fortification with vitamin D: specific modelling from National Diet and Nutrition Survey}

UK government advice to tackle low vitamin D status is described in Table 4 and comprises a blend of advice on UVB exposure, diet and supplement usage (during the winter months for the general population and all year for at-risk groups). As discussed above, fortification of widely consumed foods is a potential means to improve vitamin D status at the population level. Dr Rachel Allen (Rachel Allen Nutrition, London) presented outcomes from a modelling analysis performed to identify the fortification vehicle and concentration of vitamin D most likely to raise intakes safely in at-risk groups of the population (children aged 18-36 months; females aged 15-49 years; adults aged $>65$ years), without exceeding conservative estimates for tolerable upper limits for children $(25 \mu \mathrm{g} / \mathrm{d})$ and adults $(50 \mu \mathrm{g} / \mathrm{d})$ as set by EFSA at the time of the study ${ }^{(75)}$. The European Food Safety Authority ${ }^{(76)}$ and SACN (2016) ${ }^{(7)}$ subsequently set safe upper limits as follows: adults and children aged 11-17 years $(100 \mu \mathrm{g} / \mathrm{d})$, children aged $1-10$ years $(50 \mu \mathrm{g} / \mathrm{d})$ and infants $(25 \mu \mathrm{g} / \mathrm{d})$. Data from the first 2 years of the NDNS Rolling Programme (2008-2010) (the most current data set available at the time) were used in combination with published information on the dose-response relationship between vitamin D intake and status ${ }^{(39,40)}$. Wheat flour and milk were identified as the primary fortification vehicles of interest, due to their almost universal consumption at that time among the at-risk population subgroups included in the analysis.

The modelling predicted that fortification of wheat flour with $10 \mu \mathrm{g}$ vitamin $\mathrm{D} / 100 \mathrm{~g}$ flour would reduce the proportion of individuals in at-risk groups with intakes below $10 \mu \mathrm{g} / \mathrm{d}$ (which is now the RNI) from $93 \%$ to $50 \%$, with mean intakes increasing from $3.7 \mu \mathrm{g} / \mathrm{d}$ to $10.8 \mu \mathrm{g} / \mathrm{d}$, and there was no indication of 
any individual exceeding the tolerable upper limit. In addition, intakes improved across all socio-economic groups. This scenario was predicted to raise mean wintertime serum $25(\mathrm{OH}) \mathrm{D}$ concentration from $39 \mathrm{nmol} / 1$ (95\% CI 35, $45 \mathrm{nmol} / \mathrm{l})$ to 51 $\mathrm{nmol} / 1$ (95\% CI 43, $71 \mathrm{nmol} / \mathrm{l})$. In summary, wheat flour (fortification at $10 \mu \mathrm{g} / 100 \mathrm{~g}$ flour was the optimal level) appeared to be a more effective fortification vehicle than milk (fortified at concentrations of 0.5 to $7 \mu \mathrm{g} / 100 \mathrm{ml}$ of milk), or a combination of wheat flour and milk fortification.

Although analyses such as this ${ }^{(75)}$ are hypothetical and have limitations, simulation studies using nationally representative consumption data are important to help inform policymakers about the potential impact of fortification at a population level. Fortification of wheat flour may be an effective method for improving vitamin D status without exceeding the tolerable upper limit set for the UK. Points made during the discussion included: a need to learn from the ongoing consultation in the UK on fortification of wheat flour with folic acid (https:// www.gov.UK/government/consultations/adding-folic-acid-toflour); consideration of other types of flour that may be consumed more extensively by some ethnic minority at-risk groups, such as chapatti and gram flours (which were not included in the modelling); and, if wheat flour was to be adopted as a fortification route, the implications of avoidance of wheat flour by those choosing to avoid gluten-containing foods as a lifestyle choice. It was noted that several countries in the Middle East region (e.g. Saudi Arabia and Jordan; http://www.ffinetwork.org/regional_ activity/middle_east.php) have adopted mandatory fortification of flour with vitamin D at approximately $1.4 \mu \mathrm{g} / 100 \mathrm{~g}$.

\section{Vitamin $D_{2}$ or vitamin $D_{3}$ : which is the best form for} fortification?

Dr Louise Durrant (formerly University of Surrey) presented results from the $\mathrm{D}_{2}-\mathrm{D}_{3}$ study, which investigated differences in the efficacy of vitamin $\mathrm{D}_{2}$ and vitamin $\mathrm{D}_{3}$ supplementation on serum concentrations of total $25(\mathrm{OH}) \mathrm{D}, 25(\mathrm{OH}) \mathrm{D}_{2}$ and $25(\mathrm{OH}) \mathrm{D}_{3}$. Prior to this study, a limited but growing body of evidence suggested that vitamin $\mathrm{D}_{3}$ was more effective in raising total $25(\mathrm{OH}) \mathrm{D}$ concentration than vitamin $\mathrm{D}_{2}$. This included a systematic review and meta-analysis of RCTs that compared directly the effects of vitamin $\mathrm{D}_{2}$ and vitamin $\mathrm{D}_{3}$ on serum $25(\mathrm{OH}) \mathrm{D}$ concentration in humans, and which concluded that vitamin $\mathrm{D}_{3}$ is more effective at raising serum $25(\mathrm{OH}) \mathrm{D}$ concentration than is vitamin $\mathrm{D}_{2}{ }^{(77)}$. However, this analysis was limited by the small sample size in most of the included studies and by a high degree of heterogeneity. The $\mathrm{D}_{2}-\mathrm{D}_{3}$ study compared the efficacy of $15 \mu \mathrm{g} / \mathrm{d}$ of vitamin $\mathrm{D}_{2}$ or vitamin $\mathrm{D}_{3}$, consumed for a 12-week period within a fluid (juice) or solid (biscuit) food matrix during wintertime (October to March), on raising vitamin D status in South Asian and White European women, relative to placebo $^{(78)}$.

Participants ( $n$ 335) were recruited and randomised to receive vitamin $D_{2}$ juice, vitamin $D_{2}$ biscuit, vitamin $D_{3}$ juice, vitamin $\mathrm{D}_{3}$ biscuit or placebo ( $n$ 65-70; White European $n$ 4849; South Asian $n$ 17-19 per group). Although both vitamin
$\mathrm{D}_{2}$ and vitamin $\mathrm{D}_{3}$ raised total $25(\mathrm{OH}) \mathrm{D}$ concentrations, the vitamin $D_{3}$ biscuit and $D_{3}$ juice groups experienced significantly greater post-intervention increases in total $25(\mathrm{OH}) \mathrm{D}$ concentration, relative to the vitamin $\mathrm{D}_{2}$ biscuit and $\mathrm{D}_{2}$ juice groups, or the placebo group. Results did not differ according to the type of fortification vehicle (juice $v$. biscuit), and so the groups were combined in the analyses. Mean post-intervention 25(OH)D concentrations for women given vitamin $\mathrm{D}_{2}$ within either a biscuit $(21.4 \mathrm{nmol} / \mathrm{l})$ or juice $(17 \cdot 0 \mathrm{nmol} / \mathrm{l})$ were not only lower than at baseline $(33.7 \mathrm{nmol} / 1$ for both groups) but also lower than in the placebo group $(24.3 \mathrm{nmol} / \mathrm{l})$. This seemingly adverse influence of vitamin $\mathrm{D}_{2}$ supplementation on total $25(\mathrm{OH}) \mathrm{D}$ concentration was suggested to have contributed to the lower overall $25(\mathrm{OH}) \mathrm{D}$ status of the $\mathrm{D}_{2}$ groups.

Women of South Asian ethnicity had mean plasma total $25(\mathrm{OH}) \mathrm{D}$ concentrations below $25 \mathrm{nmol} / \mathrm{l}$ at baseline and, in the placebo group, plasma $25(\mathrm{OH}) \mathrm{D}$ fell to below 20 $\mathrm{nmol} / \mathrm{l}$ during the study. While both forms of vitamin $\mathrm{D}$ raised mean total $25(\mathrm{OH}) \mathrm{D}$ above $25 \mathrm{nmol} / \mathrm{l}$, mean concentrations were above $50 \mathrm{nmol} / \mathrm{l}$ only in the combined vitamin $\mathrm{D}_{3}$ group after the 12-week intervention. A mean total 25(OH)D concentration above $50 \mathrm{nmol} / \mathrm{l}$ was not achieved in the combined vitamin $\mathrm{D}_{2}$ group. The substantial fall in plasma $25(\mathrm{OH}) \mathrm{D}$ concentrations in South Asian women in the placebo group prompts ethical questions about the future use of RCTs with a placebo arm for vitamin D intervention studies involving South Asian women.

To our knowledge, the $\mathrm{D}_{2}-\mathrm{D}_{3}$ study is the largest RCT to date that compared specifically the effects of relatively low doses of vitamin $\mathrm{D}_{2}$ and vitamin $\mathrm{D}_{3}$ on serum total $25(\mathrm{OH}) \mathrm{D}$ in both White Europeans and South Asians. Several other trials published since 2012 have also concluded that vitamin $D_{3}$ is more effective than vitamin $\mathrm{D}_{2}$ in raising $25(\mathrm{OH}) \mathrm{D}$ concentrations, highlighting the need to update the meta-analysis conducted by Tripkovic et al. (2012) $)^{(77)}$. Further research is also required to establish whether the influence of vitamin $\mathrm{D}_{2}$ supplementation on plasma $25(\mathrm{OH}) \mathrm{D}_{3}$ concentrations is indeed a reciprocal phenomenon, as emerging evidence suggests may be the case ${ }^{(79)}$.

In summary, although both vitamin $\mathrm{D}_{2}$ and vitamin $\mathrm{D}_{3}$ raise serum $25(\mathrm{OH}) \mathrm{D}$ concentrations, the overall body of evidence from intervention trials suggests that the two forms are not equally effective. Considerations about which form of the vitamin to use should be taken into account not only when setting public health recommendations and implementing the most appropriate treatment for deficiency but also when considering the form and dose for any fortification strategies. However, there is a need to understand more about the potentially different pathways through which the two forms are metabolised, and how the body responds to the two forms. Do the two forms have different impacts on health beyond effects on total $25(\mathrm{OH}) \mathrm{D}$ concentration?

Points made in the discussion were the inherent biochemical differences in the two forms of vitamin D (e.g. molecular weight) despite the fact that they are still compared on a microgram basis, the need to explore in more depth the relative health benefits of vitamin $\mathrm{D}_{2}$ and $\mathrm{D}_{3}$, and the need for further modelling work to establish the amount of vitamin $D_{2}$ that would be required as a 
fortificant to provide equal efficacy with $\mathrm{D}_{3}$ in achieving a target $25(\mathrm{OH}) \mathrm{D}$ status, for example to inform fortification strategies that seek to use a plant-derived form of the vitamin.

The large $\mathrm{D}_{2}-\mathrm{D}_{3}$ trial described by Tripkovic et al. (2017) ${ }^{(78)}$ also provided a unique opportunity to evaluate whether the two forms of vitamin D influenced global gene expression within whole blood across the 12-week intervention period; blood samples were collected throughout the study for later transcriptome analysis. Professor Colin Smith (formerly of University of Surrey and now at University of Brighton) presented novel results from the transcriptomic analysis of ninety-eight participants (representing equal numbers of $\mathrm{D}_{3}$-supplemented, $\mathrm{D}_{2}$-supplemented and placebo-treated individuals). While many changes in gene expression were found between samples taken at baseline and after 12 weeks, they differed between the treatment groups. Although there was some overlap in changes in gene expression between the $\mathrm{D}_{2^{-}}$and $\mathrm{D}_{3}$-treated groups, most changes were either specific to the $\mathrm{D}_{3}$-treated or the $\mathrm{D}_{2}$-treated subjects. These surprising observations raise the possibility that the physiological effects of vitamins $\mathrm{D}_{3}$ and $\mathrm{D}_{2}$ may not be identical in humans ${ }^{(80)}$.

\section{Alternatives for improving vitamin D status: oral spray}

Dr Pamela Magee (Ulster University at Coleraine) provided an overview of a commercially available oral spray containing vitamin $\mathrm{D}$ and the findings from two human studies investigating its safety and efficacy. The oral spray is designed to be administered by the user under the tongue or on the inside of the cheek to allow rapid absorption via the buccal mucosa, sublingual mucosa and palatal membranes of the oral cavity. It is considered to be advantageous for individuals with intestinal malabsorption (e.g. patients with Crohn's disease) or those who may have difficulty swallowing (e.g. babies or some elderly patients in care). In the first study, healthy participants ( $n$ 22; aged $18+$ years) were recruited to receive the vitamin $\mathrm{D}_{3}$ oral spray and vitamin $\mathrm{D}_{3}$ capsules at a dose of $75 \mu \mathrm{g} / \mathrm{d}$ (3000 IU), each for a period of 4 weeks, in a randomised crossover design, with a 10-week washout period ${ }^{(81)}$. The intention of this trial was to compare the efficacy of the spray $v$. capsules in increasing vitamin D status. At baseline, approximately $18 \%$ of the study cohort had a $25(\mathrm{OH}) \mathrm{D}$ concentration $<30 \mathrm{nmol} / \mathrm{l}(9 \%<25 \mathrm{nmol} / \mathrm{l})$. Mean $25(\mathrm{OH}) \mathrm{D}$ concentration increased by $51 \%$ following supplementation with vitamin $\mathrm{D}_{3}$ capsules $(60 \mathrm{nmol} / \mathrm{l}$ to $90 \mathrm{nmol} / \mathrm{l}$ ) and by $44 \%$ after using the vitamin $\mathrm{D}_{3}$ oral spray $(60 \mathrm{nmol} / \mathrm{l}$ to $86 \mathrm{nmol} / \mathrm{l})$. No evidence of hypercalcaemia was reported, indicating that the dose and duration for both methods of supplementation were considered safe. No statistically significant difference between the two supplementation groups was found, in contrast with another study conducted in India, which compared a lower dose (1000 IU/d) vitamin D spray with capsules, and found that the spray raised $25(\mathrm{OH}) \mathrm{D}$ concentration significantly more than the capsules ${ }^{(82)}$. These contrasting findings might be due to differences in study design (sample size, dose and washout period), lower intestinal absorption and membrane permeability in Asian compared with White European participants ${ }^{(83)}$, or genetic variation in vitamin $\mathrm{D}$ receptor polymorphisms known to influence vitamin D metabolism ${ }^{(84)}$. In the study of Satia et al. ${ }^{(82)}, 7 \%$ of the cohort of healthy individuals had plasma vitamin D concentrations $<25 \mathrm{nmol} / \mathrm{l}$ at baseline, which was similar (9\%) in the study of Todd et al. $(2016)^{(81)}$.

A second study involving Gaelic footballers (mean age 20 (SD 2) years) compared the same vitamin $D_{3}$ oral spray used by Todd et al. (2016) in a 12-week randomised double-blinded placebocontrolled trial conducted during wintertime ${ }^{(85)}$. At baseline, $22 \%$ of participants had a $25(\mathrm{OH}) \mathrm{D}$ status $<30 \mathrm{nmol} / \mathrm{l}$. The mean $25(\mathrm{OH}) \mathrm{D}$ concentrations in the intervention (47.4 (SD 13.3) nmol/l; $n$ 22) and placebo groups (43.1 (sD 22.0) nmol/l; $n 20)$ were below $50 \mathrm{nmol} / \mathrm{l}$. Post-intervention 25(OH)D concentrations in the vitamin $\mathrm{D}_{3}$ oral spray group $(83.7(\mathrm{sD} 33.0) \mathrm{nmol} / \mathrm{l})$ were significantly greater than in the placebo group (49.2 (SD $25.4) \mathrm{nmol} / \mathrm{l}$ ), and there was a significantly greater increase in 25(OH)D concentrations (change from baseline: $36 \cdot 31$ (SD 32.34) v. 6.11 (SD 23.93) nmol/1, respectively). Compliance and acceptance of the mode of application appeared good.

The risk of excessive use (especially with high-dose sprays intended for a single spray dosing regimen) was discussed. Avoiding excessive intake by over-use of the spray would be a particularly important challenge; clear guidance and education on the frequency of use would be critical for all age groups but especially in younger and older populations. Certainly, the above referenced studies showed the spray to be safe and effective. Of specific relevance, the spray may be of key benefit for those with gastro-intestinal malabsorption or swallowing difficulties. The balance between potential difficulties in using a spray for older people with compromised hand movement (grip strength, dexterity) versus the advantage of avoiding adding supplements to the existing medication requirements of care home residents was also discussed.

In summary, oral spray vitamin $\mathrm{D}_{3}$ appears to be as effective as capsule supplementation at increasing total $25(\mathrm{OH}) \mathrm{D}$ concentrations in healthy White UK adults. Further research is needed to confirm the efficacy of vitamin D oral spray in comparison with capsules in other ethnic groups.

\section{Considerations for the implementation of fortification strategies by industry}

If the current UK government vitamin D policy, which includes the use of vitamin D supplements during the winter months (and all year for at-risk groups, including those unable to spend time outdoors), fails, other approaches to increase vitamin $D$ intake will be needed urgently. The final session focused on 'real-world' issues associated with implementing food fortification strategies. As with all food fortification programmes, there is the risk of excess nutrient intake, but the success of Finland and other countries in their national vitamin D food fortification strategies is a good demonstration that it can be done safely and effectively and make a real difference to population intake ${ }^{(71)}$.

Gael Delamare (Campden BRI) provided an overview of the technical and consumer considerations associated with potential fortification vehicles for vitamin $\mathrm{D}$, noting that choice of vehicle (and form of the vitamin) may allow targeting to particular 
consumer groups, according to age, dietary preferences, region or other characteristics. Factors to be considered include: consumer acceptability and preference; shelf-life of the fortified products and stability of the fortificant over time; and the relative healthiness of the food vehicle (to avoid a fortificant being added to a food not considered healthy). To ensure consumer acceptability, changes to the sensory characteristics (e.g. taste, texture and smell) need to be minimised. Processing using heat may affect stability, and different ways of cooking foods (e.g. boiling, frying or baking) may also impact on the final vitamin D content and bioavailability in the prepared food. The ability of a particular approach to raise vitamin D status will be dependent on the amount of the food consumed and on any food matrix components (e.g. fibre or lipids) that affect absorption. The use of UV light to irradiate bread for $1-5 \mathrm{~s}$ prior to packaging was given as an example of a means to use processing to enhance vitamin $\mathrm{D}_{2}$ content; this technique has been approved for use by $\mathrm{EFSA}^{(86)}$.

Another consideration is the legal requirements for foods carrying a nutrition claim. Regulation specifies the amount required to be present in order to permit a claim (15\% of the reference intake, RI $(5 \mu \mathrm{g} / \mathrm{d})$ per $100 \mathrm{~g}$, per $100 \mathrm{ml}$ or per portion of food, or $7.5 \%$ of the RI per $100 \mathrm{ml}$ for beverages). Challenges associated with this are discussed below.

Measuring the vitamin D content of foods presents a challenge in itself as vitamin $D$ is present only in small $(\mu \mathrm{g})$ quantities. The process includes extraction of vitamin $\mathrm{D}$ from the food matrix, followed by analysis using the preferred LC MS/MS method, which is time (about 60 min per sample) and labour intensive.

In summary, consumer attitude is of importance in the choice of a fortificant and food vehicle. Currently, there are no guidelines on the most suitable processes for each food vehicle, e.g. acceptable levels for fortification. Processing can help increase vitamin D concentrations in foods (e.g. UV irradiation). However, bioavailability of vitamin D from different matrices needs further investigation to identify the most effective vehicles. Quantifying the concentration of vitamin D in the food measures the amount present, not the amount available for absorption. Labelling requirements present a challenge.

\section{Case studies from industry}

Alexa Hoyland (Kellogg Company), Lise Larsen (Arla Foods) and Laura Street (Marks \& Spencer PLC) provided insights into the approaches being taken by food businesses to enhance dietary vitamin $\mathrm{D}$ intake through food fortification and the associated challenges.

Fortified ready-to-eat cereals play a recognised role in micronutrient provision in Europe and worldwide. The Kellogg Company fortification policy ensures that foods are fortified according to several considerations. These include: (i) the nutrient intake and shortfalls of population subgroups globally; (ii) national laws and regulations; (iii) technical feasibility of the addition of a given fortificant and (iv) occasions and frequency of consumption of the food. Kellogg Europe began fortification with vitamin D in the early 2000s, more laterly pledging to fortify all children's cereals with vitamin D. Between 2011 and 2014, all children's cereal products were fortified to provide $25 \%$ of the
European RI per serving (the European RDA of $5 \mu \mathrm{g} / \mathrm{d}$ is used as the RI in the labelling legislation), with the majority of the range available in the EU being fortified with $50 \%$ of the RI per serving by 2018. It is estimated that 5.2 billion portions of vitamin D-fortified cereal were sold within Europe during 2019. Most retailers now fortify their own brands of cereals.

The importance of the need for simplicity in relation to fortification was emphasised, in terms of a simple supply chain solution that can be deployed across European markets with varying requirements. Differences in: (1) consumer attitudes; (2) regulation; (3) practical applications and (4) messaging were four key areas highlighted. The regulatory landscape within Europe is complex, with fortification of foods permitted in some countries (e.g. UK, Austria, Finland, Sweden) and prohibited in others (Norway and Denmark), whereas fortification of cereal products in Germany is tightly restricted and dependent on the fortificant used and product type (e.g. muesli $v$. whole wheat cereals). In practical terms, vitamin D is heat-sensitive and so is added at the end of manufacturing using a spray method to provide a coating, thus limiting exposure to light and temperature. An approximate $30 \%$ 'overage' is included in the amount added to allow for losses during the shelf life of the product, and to ensure that legal requirements are met (i.e. that the stated amount is present throughout the shelf life of the product).

Vitamin $\mathrm{D}_{3}$ is most commonly sourced from lanolin extracted from sheep's wool, which is not acceptable to those following a strict vegan diet, for whom fungus-derived vitamin $D_{2}$ is the form of choice. However, compared with vitamin $D_{2}$, use of vitamin $D_{3}$ as the fortificant is advantageous in terms of cost, bioavailability, shelf stability and the reliability of supply. With the growing interest in plant-based eating and flexitarian diets, and the increased availability of vegan-style foods, there is increasing pressure from some consumers for manufacturers to fortify foods with vitamin $\mathrm{D}_{2}$ (rather than $\mathrm{D}_{3}$ ). (Vegetarians and vegans comprise about $3 \%$ and $1 \%$ of the population, respectively (according to data from the government's Food and You Survey, wave 5 (April 2019)) https://www.food.gov.UK/research/food-and-you/foodand-you-wave-five). Overall, however, market research indicates that 'fortified with vitamin D' is a valued health claim in the UK population with evidence that it is a driver of purchasing. Nevertheless, there is also a tension between desire for fortification and a growing consumer interest in minimally processed 'natural' products, with short ingredient lists comprising recognisable kitchen ingredients, which might predicate against fortification in some food formats.

Manufacturers have an important role to play in the sharing of information on vitamin D and raising awareness about the need for vitamin D and its benefits. Improved consumer awareness of vitamin $\mathrm{D}$ fortification in a product can be achieved through several approaches, including powerful communication and claims techniques across packaging, social media, television and public relations activity, as well as engagement with healthcare professionals and strategic partnerships.

Lise Larsen outlined the specific approach taken by Arla Foods. In general, products are fortified only if there is documented evidence of low intakes or low status of the vitamin or mineral in the target group. On this basis, Arla Foods considers vitamin $\mathrm{D}$ fortification relevant in all markets where it operates, 
but different local regulations and consumer preferences influence which products are fortified in practice. Vitamin D fortification of drinking milk is mandatory (Sweden) and highly encouraged by authorities (Finland). In both countries, Arla Foods fortifies all milk with $1.0 \mu \mathrm{g}$ vitamin D per $100 \mathrm{ml}$. In Sweden, it is mandatory to fortify plain yogurts but there is no requirement for flavoured yogurts; Arla fortifies both plain and flavoured yogurts. Likewise, they fortify most plain and flavoured yogurts in Finland (see earlier Section on vitamin D fortification in Finland) because fortification of both product types is highly encouraged by authorities. For flavoured milk drinks sold in Sweden and Finland, there are no regulatory requirements or encouragement from authorities to fortify with vitamin D; Arla Foods fortifies some of the flavoured milk drinks sold in these countries.

In the UK and Denmark, where vitamin D fortification is not regulated by law or specifically encouraged by authorities, Arla Foods fortifies very few products; only two UK products are currently fortified with vitamin $\mathrm{D}$. A fluid milk product fortified with vitamin D, launched in 2017, was removed from the market after less than a year because of low sales. The same happened in Denmark, which was assumed to indicate that consumers did not value fortified milk products.

The lack of consistency between the RI (or RDA) for vitamin D that must be used for labelling purposes $(5 \mu \mathrm{g} / \mathrm{d})$ and the UK government's RNI $(10 \mu \mathrm{g} / \mathrm{d})$ was highlighted as a challenge by several speakers. This inconsistency makes it difficult for manufacturers to communicate clearly to consumers and increases the potential for consumers to feel misled. For example, a claim that a product provides $50 \%$ of the RI (as required by labelling regulations) might be interpreted to mean a content of $5 \mu \mathrm{g}$ (half of the amount advocated per day by the UK government) rather than $2.5 \mu \mathrm{g}$. Furthermore, the wording used is restricted, and so labelling has to refer to the RI rather than to more user friendly words such as 'daily needs'.

This discrepancy between labelling regulations and the UK $\mathrm{RNI}(5 \mu \mathrm{g} v \cdot 10 \mu \mathrm{g}$, respectively) means that food producers are unable to explain simply to consumers how much of the UK RNI for vitamin D is met by a portion of their product.

Manufacturers can improve consumer understanding by providing examples on websites and other communication tools about how consumers can incorporate various foods into their diets to achieve their recommended daily intake (e.g. a portion of salmon, boiled egg, fortified cereal and a fortified dairy product). However, the reality is that even within categories (e.g. yogurts), fortification is not consistently used and so this may be confusing for customers. Similarly, taking a decision about whether or not to consume supplements routinely may be challenging for those who already consume some fortified foods, given that fortification does not apply to all foods in a category, fortification levels vary, and on-pack claims are obliged to follow labelling regulations and refer to $5 \mu \mathrm{g} / \mathrm{d}$ rather than the UK government's RNI of $10 \mu \mathrm{g} / \mathrm{d}$.

Laura Street (Marks \& Spencer PLC) reminded Forum participants that public health has to compete with a plethora of trends, fashions and 'noise' around nutrition, making it challenging to achieve 'cut through' and to help educate the population with messaging on vitamin D, a genuine health need. She discussed linking vitamin D fortification strategies with popular food, ingredient or health trends, to gain traction with consumers, but noted that whilst some express an interest in health, in reality, convenience, price and simplicity remain important factors. Furthermore, she cautioned that what customers say in surveys may be different to real-world consumer behaviour when shopping. Consumer behaviour may also be inconsistent, with some people following a healthier dietary pattern during the week and being more indulgent at the weekends. Also, time of day and day of the week influence eating behaviours.

Since 2014, all Marks \& Spencer bread has been fortified with vitamin $\mathrm{D}_{2}$ and the price of a standard loaf of bread has recently been lowered (to $65 \mathrm{p}$ per loaf). Fortification vehicles that are highly recognisable and widely available appear to be the best option and can decrease cost. It is also beneficial if fortification presents an added value to the consumer that will motivate them to choose a particular product.

Several speakers referred to the potential merits of a code of practice for industry, or more coordinated action involving government, industry and other stakeholders. The need to recognise anti-competition law was also flagged, in situations where multiple partners from the same sector are involved in an initiative.

\section{General discussion}

Several themes emerged from the discussion, which are summarised below.

If over time, it transpires that there has been insufficient improvement in the nation's vitamin D status, what might plan B look like?

Current UK government policy refers to the role of sunlight exposure during the summer months and foods as a source of vitamin D but places emphasis on vitamin D supplementation especially during the winter months and all year round for groups considered to be at risk of low status (see Table 4). Given the limited impact of advice on use of folic acid supplements in the UK and concerns about excessive sun exposure in terms of skin cancer risk, improved understanding of dietary sources of vitamin D and also, potentially, a fortification strategy are the obvious options for improving vitamin D status.

There was discussion about the types of food that might be considered appropriate for fortification. There is some important learning from the RCTs discussed above. The importance of realworld considerations was emphasised, in particular attention given to foods consumed regularly by groups who may be at-risk of low vitamin $\mathrm{D}$ intakes, and whether it is inappropriate to add vitamin D to foods that do not contain it naturally, which would severely restrict the options available. Previous modelling studies have focused on bread flour, given the widespread consumption of bread and current UK policy for mandatory addition of several nutrients to bread flour. Discussion focused on whether fortification of wheat flour alone would reach the most 'at-risk' groups (who may consume other flours) and the practical and processing challenges already evident from discussions around proposals to add folic acid to bread flour. 
Examples were given of vitamin D fortification approaches in Finland, where fortification was 'promoted' by the government, and in the USA, where fortification was agreed as a result of coordination between food industry stakeholders. If fortification was to be agreed by industry stakeholders as a desirable approach, then appropriate messaging (e.g. via social media) might then be determined. Another example concerned mandatory fortification of wheat flour in Mongolia (with multiple micronutrients) triggered by the incidence of rickets. An initial public survey prior to fortification indicated that $55 \%$ of urban and rural Mongolians favoured fortification, but after learning about the importance of vitamin $\mathrm{D}$ for the prevention of rickets, the percentage favouring fortification increased to $75 \%(87)$.

The discrepancy between the EU labelling requirements for vitamin D (RI of $5 \mu \mathrm{g} / \mathrm{d}$ ) and the UK RNI of $10 \mu \mathrm{g} / \mathrm{d}(400 \mathrm{IU} / \mathrm{d}$ ) was discussed as a potential barrier to voluntary fortification by companies. Industry nutritionists considered that whilst it is not a barrier per se, it compromises clear communication. Nevertheless, it has been estimated that if everyone consumed $5 \mu \mathrm{g} / \mathrm{d}$, then it would reduce the population prevalence of a $25(\mathrm{OH}) \mathrm{D}$ concentration $<25 \mathrm{nmol} / \mathrm{l}$ to $<10 \%{ }^{(88)}$. So, to aim for consolidating current intakes (shown in Table 3) to this level could be a starting point. An Industry representative suggested that establishing a requirement for mandatory fortification would create a more level playing field for all consumers, as well as for industry.

\section{Need for real-world information}

To move things forward, the need for 'real-world' information on the economic implications of vitamin D fortification for industry was stressed. This is key in order to explore fortification as a viable solution to increasing vitamin $\mathrm{D}$ intakes, along with a more collaborative working relationship between the research community, policymakers and industry. For food businesses, the cost of fortification is influenced by: (i) the type of fortificant; (ii) the point at which it is added to the product; (iii) the need for quality control; (iv) the volumes being purchased; (v) the product category and (vi) the profit margin between and within different food categories. For the breakfast cereal industry, vitamin D is one of the most expensive fortificants currently added because of the cost of the technologies required to add the vitamin, rather than the cost of the vitamin per se. However, the cost will be dependent on the nature of the technology needed and whether it is $\mathrm{D}_{2}$ or $\mathrm{D}_{3}$ that is added. For example, the cost of adding vitamin $\mathrm{D}$ is less for dairy-based foods and so is not perceived to be a major economic hurdle.

For those researchers engaged in modelling, estimations of costs rely on published sources of information where they exist. Examples used were 25(OH)D biofortification of eggs, in which the cost per dozen eggs was deemed minimal (approximately $0 \cdot 1$ p per dozen eggs) and vitamin D fortification of flour, estimated as approximately $1 \mathrm{p}$ per tonne.

Experience from ODIN has demonstrated that modelling the impact of flour fortification is difficult, due to imports/ exports and the variety of products in which flour is used. In modelling the effects of fortification, the distribution of intakes was more important than the lower and upper extremes of intake, and the potential use of supplements has to be taken into account.
A need was identified for fortification models that could be responsive to changing patterns of consumption, to ensure that they reflect changes in the level of intake and sources of vitamin D.

How can consumer understanding about vitamin $D$

\section{be improved?}

This topic attracted considerable debate and discussion that focused on articulating vitamin D content of foods in a simple, unambiguous way that is also compliant with regulations. It was agreed that communication to consumers remains difficult for the reasons outlined above. Linked with this was the need to understand better the public's knowledge about the relevance of adequate vitamin $\mathrm{D}$ status for health, how this might be achieved, and the role of vitamin D supplementation in achieving this goal. There is a need for such insight for the health and social care community as well as the general public. The Forum took place before the COVID-19 pandemic but the importance of improving the public's understanding about vitamin $\mathrm{D}$ has subsequently been highlighted because opportunities for synthesis of vitamin D following sunlight exposure will have been reduced for those people spending more time indoors during the lockdown.

Greater understanding about where members of the public obtain scientific information might help inform which communication channels may be best utilised. In principle, multiple media avenues should be considered, including for example having a well-known person with a track record of science advocacy to champion and communicate the message. Consideration was also given to what might 'capture the imagination' of the public, and whether this might require using a high profile case of a vitamin D deficiency-related death to help people recognise the importance of vitamin $\mathrm{D}$ to their own health.

It was agreed that a multi-pronged approach may be needed, involving the food and health sectors, government and other stakeholders, and that there is not necessarily a universal solution. In particular, the benefits of some form of code of practice developed by food manufacturers, ingredients suppliers and retailers in association with other stakeholders were discussed. The code of practice might provide guidance on the most appropriate foods, vitamin D sources and fortification levels and suggest strategies for specified food categories.

The role of the supplements industry was also discussed. Currently, many popular supplements contain more than the recommended $10 \mu \mathrm{g} / \mathrm{d}$. High intakes of vitamin D through consumption of fortified foods alone are highly unlikely to create a problem in relation to tolerable upper intake levels, and the modelling conducted in the ODIN project indicates that even those people taking high dose supplements $(50 \mu \mathrm{g} / \mathrm{d})$, in addition to fortified foods, would be unlikely to reach the tolerable upper level of intake.

\section{Considerations for at-risk population groups}

There was discussion around the lack of an affordable plantbased source of vitamin $\mathrm{D}$ (i.e. vitamin $\mathrm{D}_{2}$ or a synthetic form of $\mathrm{D}_{3}$ ) for use as a fortificant in vegan, Halal and Kosher products, and how the sourcing of the two forms of vitamin D could 
best be communicated. There was also discussion about how to direct vitamin D public health messages and specific vitamin D imagery to at-risk BAME ethnic groups living in the UK without raising concerns about discrimination or causing offence. Advocacy approaches (e.g. through community leaders or Faith groups) may be more effective than public health messages per se, such as those delivered by health professionals or media campaigns, because in 'advocacy' approaches, people receive the information from someone they know. As an example, this approach has proved effective in the context of spreading information about childhood rickets prevention in at-risk population groups. General practitioners may also be a route to increasing awareness due to their high level of contact with all members of the public (approximately $90 \%$ within a 3 -year period). There was also discussion about the need for periodic updates or refreshers for healthcare professions to ensure that vitamin D messaging remains front of mind and aligned with recommendations; and that advice is given routinely about supplementation, in general; and Healthy Start vitamins for young children, in particular.

The importance of monitoring was highlighted. SACN's research recommendations included the need for monitoring vitamin D status among ethnic minority groups, as well as infants and children under 4 years, exclusively breastfed infants, pregnant and lactating women.

It was observed that individuals following a vegan diet are not included in the recommendations for vitamin D supplementation, despite the fact that most foods that naturally contain vitamin $\mathrm{D}$ are of animal origin and there are limited food sources of the plant form of vitamin $\mathrm{D}$ (i.e. vitamin $\mathrm{D}_{2}$ ). It was acknowledged that vitamin $\mathrm{D}$ status in vegan groups may be of concern, especially in light of the recent trend among adolescents and younger adults to adopt a vegan style of eating; and the concurrent statistics for vitamin D adequacy in this age group (see Table 2). Public Health England identified insufficient data to make specific recommendations for vegans, who should follow more general advice on UVB skin exposure and inclusion of vitamin D-fortified foods in the diet. The difficulties associated with monitoring intakes among vegans (and indeed vegetarians), specifically, using NDNS data were also highlighted. This is due to the relatively small percentage of these groups within the population as a whole (estimated to be about 1 and $3 \%$, respectively, see above) and therefore present in the NDNS sample.

In conclusion, it was agreed that further discussion, including food businesses, researchers and public health nutritionists, was needed to share knowledge, articulate the issues further and develop a 'road map' for improving vitamin D status in the UK.

\section{Acknowledgements}

Both S.A. Lanham-New and J.L. Buttriss express their sincere thanks to the Rank Prize Funds Nutrition Committee for their financial support of this meeting and for their encouragement in its organisation. The paper is not a Consensus Statement but is a summary of the discussions that took place at this 2nd
Rank Forum on Vitamin D. The Forum took place before the COVID-19 pandemic in September 2019, but finalisation of the Manuscript has occurred during it.

This Rank Forum on Vitamin D was supported financially by a Rank Prize Funds Forum Award to S.A. Lanham-New. The views are those of the Forum delegates as expressed in their presentations and summarised in this document, and not those of the Rank Prize Funds Nutrition Committee or Trustees.

J. B. and S. A. L.-N. wrote the application for approval for Workshop funding. J. B., S. A. L.-N. and S. S. were primarily responsible for the Workshop content, conception, drafting and critical review of the manuscript. J. C. M. and A. P. (Senior Author) were the Workshop Chairs. A. P., J. C. M. and L. L. provided critical review of the manuscript during drafting and the revisions made following peer review. All authors either contributed to the manuscript content through expert presentations delivered at the Forum and/or discussions held during the Forum that informed writing of the manuscript. All authors approved the final version of the manuscript.

R. A., J. B., K. D. C., A. L. D., G. D., A. H., M. K., L. L., L. L., P. M., J. C. M., A. P., C. P. S., S. S., L. S. and G. S. declare no conflict of interest. S. U. has received travel grants and a speaker fee from Internis Pharmaceutical and travel grants and a speaker fee from Thornton \& Ross Pharmaceuticals. S. A. L-N. has received speaker fees from Thornton \& Ross Pharmaceuticals and is Research Director for D3Tex Ltd, which holds the UK and Gulf Corporation Council (GCC) Patents for the use of UVB material for preventing vitamin D deficiency. T. H. is the lead academic collaborator in two Innovate UK-funded research projects involving Noble Foods Ltd and DSM Ltd, which aim to explore the commercial potential for vitamin D-enriched egg (https://www.gov.uk/government/publications/inno vate-uk-funded-projects). T. H. has also received speaker honoraria in the past from DSM Ltd. A. Prentice, K. D. C. and S. A. L-N. were members of the Scientific Advisory Committee on Nutrition (SACN) Working Group on Vitamin D, which was responsible for reviewing the scientific evidence leading to publication of the Vitamin D and health report (2016). G. S. was also a contributor to this report. L. L. was Head of Nutrition Science at Public Health England (PHE) at the time of the Forum (September 2019). A. P. and J. C. M. are members of the Rank Prize Funds Committee and served as co-chairs for the Forum.

All participants in this 2nd Rank Forum on Vitamin D were provided with Travel Grants from the Rank Prize Funds to enable attendance.

\section{References}

1. NHS Digital (2020) Vitamin D: Coronavirus Update. https:// www.nhs.uk/conditions/vitamins-and-minerals/vitamin-d/ (accessed September 2020).

2. Lanham-New SA, Webb AR, Cashman KD, et al. (2020) Vitamin D and SARS-CoV-2 virus/COVID-19 disease. BMJ Nutr Prev Health 3, 106-110. 
3. NICE (National Institute for Health and Care Excellence) (2020) Evidence reviews for the use of vitamin D supplementation as prevention and treatment of COVID-19. https://www.nice.org. uk/guidance/ng187/evidence (accessed July 2021).

4. SACN (Scientific Advisory Committee on Nutrition) (2020) Update of rapid review: Vitamin D and acute respiratory tract infections. https://www.gov.uk/government/publications/ sacn-rapid-review-vitamin-d-and-acute-respiratory-tract-infe ctions (accessed July 2021).

5. Lanham-New SA, Buttriss JL, Miles LM, et al. (2011) Proceedings of the rank forum on vitamin D. Br J Nutr 105, 144-156.

6. DH (Department of Health) (1991) Dietary Reference Values for Food Energy and Nutrients for the United Kingdom. Report of the Panel on Dietary Reference Values of the Committee on Medical Aspects of Food Policy. London: TSO.

7. SACN (2016) Vitamin D and Health Report. Public Health England. https://www.gov.uk/government/publications/sacnvitamin-d-and-health-report (accessed December 2019).

8. Defra (Department for Environment, Food and Rural Affairs) (2014) Consultation on revoking Regulation 4 of the Spreadable Fats (Marketing Standards) and Milk and Milk Products (Protection of Designations) (England) Regulations 2008 Margarine Fortification: Summary of Response. https://assets. publishing.service.gov.uk/government/uploads/system/uploads/ attachment_data/file/287673/margarine-fortification-sum-resp201403.pdf (accessed December 2019).

9. EC (European Commission) (2006) Commission Directive 2006/141/EC of 22 December 2006 on infant formulae and follow-on formulae and amending Directive 1999/21/EC Text with EEA relevance. Off $J \mathbf{L} \mathbf{4 0 1}, 1-33$

10. Prentice A (2007) Elsie Widdowson Lecture 2006 Mining the depths: metabolic insights into mineral nutrition: symposium on "Nutrition in early life: new horizons in a new century. Proc Nutr Soc 66, 512-521.

11. Bouillon R \& Bikle D (2019) Vitamin D metabolism revised: fall of Dogmas. J Bone Miner Res 34, 1985-1992.

12. IOM (Institute of Medicine) (2011) Dietary Reference Intakes for Calcium and Vitamin D. Washington, DC: The National Academes Press.

13. MacDonald HM, Mavroeidi A, Fraser WD, et al. (2011) Sunlight and dietary contributions to the seasonal vitamin d status of cohorts of healthy postmenopausal women living at northerly latitudes: a major cause for concern? Osteoporosis Int $\mathbf{2 2}$ 2461-2472.

14. Darling AL, Hart KH, Macdonald HM, et al. (2013) Vitamin D deficiency in UK South Asian women of childbearing age: a comparative longitudinal investigation with UK Caucasian women. Osteoporosis Int. 24, 477-488.

15. Farrar MD, Kift R, Felton SJ, et al. (2011) Recommended summer sunlight exposure amounts fail to produce sufficient vitamin D status in UK adults of South Asian origin. Am J Clin Nutr 94, 1219-1224.

16. Roberts C, Steer T, Maplethorpe N, et al. (2018) National Diet and Nutrition Survey Results from Years 7 and 8 (combined) of the Rolling Programme (2014/2015-2015/2016). PHE Publications. https://www.gov.uk/government/statistics/ndns-results-fromyears-7-and-8-combined (accessed December 2019).

17. Bates, B., Collins, D., Jones, K., Page, P., Roberts, C. \& Swan, G.(2020) National Diet and Nutrition Survey Rolling programme Years 9 to $11(2016 / 2017$ to $2018 / 2019)$. Public Health England. Available from: https://www.gov.uk/ government/statistics/ndns-results-from-years-9-to-11-2016to-2017-and-2018-to-2019 (accessed July 2021).

18. Lennox A, Sommerville J, Ong K, et al. (2013) Diet and Nutrition Survey of Infants and Young Children. Department of Health and Food Standards Agency. https://www.gov.uk/ government/publications/diet-and-nutrition-survey-of-infantsand-young-children-2011 (accessed December 2019).

19. Bates B, Collins D, Cox L, et al. (2019) National Diet and Nutrition Survey Results from Years 1 to 9 of the Rolling Programme (2012/2013-2013/2014): Time Trend and Income Analysis. PHE Publications. https://www.gov.uk/gover nment/statistics/ndns-time-trend-and-income-analyses-foryears-1-to-9 (accessed December 2019).

20. PHE (Public Health England) (2016) PHE Publishes New Advice on Vitamin D (Press Release). https://www.gov.uk/ government/news/phe-publishes-new-advice-on-vitamin-d (accessed June 2020).

21. NatCen Social Research (2015) Royal Free and University College Medical School, Department of Epidemiology and Public Health. Health Survey for England, 2010. [data collection]. 3rd Edition. UK Data Service. SN: 6986. http://doi.org/ 10.5255/UKDA-SN-6986-3 (accessed August 2021).

22. Darling AL, Blackbourn DJ, Ahmadi KR, et al. (2018) Vitamin D supplement use and associated demographic, dietary and lifestyle factors in 8024 South Asians aged 40-69 years: analysis of the UK Biobank cohort. Public Health Nutr 21, 2678-2688.

23. Darling A (2020) Vitamin D deficiency in western dwelling South Asian populations: an unrecognised epidemic. Proc Nutr Soc 79, 259-271.

24. Fry A, Littlejohns TJ, Sudlow C, et al. (2017) Comparison of sociodemographic and health-related characteristics of uk biobank participants with those of the general population. Am J Epidemiol 186, 1026-1034.

25. Kiely M \& Cashman KD (2018) Summary outcomes of the ODIN project on food fortification for vitamin D deficiency prevention. Int J Environ Res Public Health 15, E2342.

26. Binkley N, Krueger D, Cowgill CS, et al. (2004) Assay variation confounds the diagnosis of hypovitaminosis D: a call for standardization. J Clin Endocrinol Metab 89, 3152-3157

27. Sempos CT, Vesper HW, Phinney KW, et al. (2012) Vitamin D status as an international issue: national surveys and the problem of standardization. Scand J Clin Lab Invest Suppl 243, 32-40

28. Cashman KD, Kiely M, Kinsella M, et al. (2013) Evaluation of vitamin D standardization program protocols for standardizing serum 25-hydroxyvitamin D data: a case study of the program's potential for national nutrition and health surveys. Am J Clin Nutr 97, 1235-1242.

29. Cashman KD, Dowling KG, Škrabáková Z, et al. (2016) Vitamin D deficiency in Europe: pandemic? Am J Clin Nutr 103, 1033-1044.

30. Cashman KD (2019) Vitamin D deficiency: defining, prevalence, causes, and strategies of addressing. Calcif Tissue Int. 106, 14-29.

31. O'Neill CM, Kazantzidis A, Ryan MJ, et al. (2016) Seasonal changes in vitamin D-effective UVB availability in Europe and associations with population serum 25-hydroxyvitamin D. Nutrients $\mathbf{8}, \mathrm{E} 533$.

32. Roman Vinas B, Ribas Barba L, Ngo J, et al. (2011) Projected prevalence of inadequate nutrient intakes in Europe. Ann Nutr Metab 59, 84-95.

33. Gallo S, Comeau K, Vanstone C, et al. (2013) Effect of different dosages of oral vitamin D supplementation on vitamin D status in healthy, breastfed infants: a randomized trial. JAMA 309, $1785-1792$

34. ní Chaoimh C, McCarthy EK, Murray DM, et al. (2016) Low prevalence of vitamin D deficiency in Irish preschoolers despite northerly latitude and high prevalence of inadequate intakes. Proc Nutr Soc 75, E213. 
35. El Hayek J, Pham TT, Finch S, et al. (2013) Vitamin D status in Montreal preschoolers is satisfactory despite low vitamin D intake. J Nutr 143, 154-160.

36. Mortensen C, Damsgaard CT, Hauger H, et al. (2016) Estimation of the dietary requirement for vitamin $\mathrm{D}$ in white children aged 4-8 y: a randomized, controlled, dose-response trial. Am J Clin Nutr 104, 1310-1317.

37. Ohlund I, Lind T, Hernell O, et al. (2017) Increased vitamin D intake differentiated according to skin color is needed to meet requirements in young Swedish children during winter: a double-blind randomized clinical trial. Am J Clin Nutr 106, 105-112.

38. Smith TJ, Tripkovic L, Damsgaard CT, et al. (2016) Estimation of the dietary requirement for vitamin $\mathrm{D}$ in adolescents aged 14-18 years: a dose-response, double-blind, randomized placebo-controlled trial. Am J Clin Nutr 104, 1301-1309.

39. Cashman KD, Hill TR, Lucey AJ, et al. (2008) Estimation of the dietary requirement for vitamin $\mathrm{D}$ in healthy adults. Am J Clin Nutr 88, 1535-1542.

40. Cashman KD, Wallace JM, Horigan G, et al. (2009) Estimation of the dietary requirement for vitamin $\mathrm{D}$ in free-living adults $>=64$ years of age. Am J Clin Nutr 89, 1366-1374.

41. Kiely M, Hemmingway A \& O'Callaghan KM (2017) Vitamin D in pregnancy: current perspectives and future directions. Ther Adv Musculoskelet Dis 9, 145-154.

42. Saraf R, Morton SMB, Camargo CA, et al. (2016) Global summary of maternal and newborn vitamin D status - a systematic review. Maternal Child Nutr 12, 647-668.

43. Roth DE, Leung M, Mesfin E, et al. (2017) Vitamin D supplementation during pregnancy: state of the evidence from a systematic review of randomised trials. BMJ 359, j5237.

44. Palacios C, Kostiuk LK \& Pena-Rosas JP (2019) Vitamin D supplementation for women during pregnancy. Cochrane Database Syst Rev 7, CD008873.

45. Palacios C, Trak-Fellermeier MA, Martinez RX, et al. (2019) Regimens of vitamin D supplementation for women during pregnancy. Cochrane Database Syst Rev 10, CD013446.

46. Kiely M, O'Donovan SM, Kenny LC, et al. (2017) Vitamin D metabolite concentrations in umbilical cord blood serum and associations with clinical characteristics in a large prospective mother-infant cohort in Ireland. J Steroid Biochem Mol Biol 167, 162-168.

47. Munns CF, Shaw N, Kiely M, et al. (2016) Global consensus recommendations on prevention and management of nutritional rickets. J Clin Endocrinol Metab 101, 394-415.

48. O'Callaghan KM, Hennessy A, Hull GLJ, et al. (2018) Estimation of the maternal vitamin D intake that maintains circulating 25-hydroxyvitamin $\mathrm{D}$ in late gestation at a concentration sufficient to keep umbilical cord sera $>/=25-30 \mathrm{nmol} / \mathrm{l}$ : a dose-response, double-blind, randomized placebo-controlled trial in pregnant women at northern latitude. Am J Clin Nutr 108, 77-91.

49. Uday S, Fratzl-Zelman N, Roschger P, et al. (2018) Cardiac, bone and growth plate manifestations in hypocalcemic infants: revealing the hidden body of the vitamin D deficiency iceberg. BMC Pediatr 18, 183.

50. Goldacre M, Hall N \& Yeates DGR (2014) Hospitalisation for children with rickets in England: a historical perspective. Lancet 383, 597-598.

51. Julies P, Lynn RM, Pall K, et al. (2020) Nutritional rickets under 16 years: UK surveillance results. Arch Dis Child. 105:587-592.

52. Uday S \& Hogler W (2020) Response Letter to Nutritional Rickets Under 16 Years: UK Surveillance Results. https://adc. bmj.com/content/105/6/587.responses (accessed September 2020).
53. Thatcher TD, Pludowski P, Shaw NJ, et al. (2016) Nutritional rickets in immigrant and refugee children. Public Health Rev 37, 3 .

54. Uday S \& Hogler W (2018) Prevention of rickets and osteomalacia in the UK: political action overdue. Arch Dis Child. 103, 901-906.

55. Uday S, Kongjonaj A, Aguiar M, et al. (2017) Variations in infant and childhood vitamin D supplementation programmes across Europe and factors influencing adherence. Endocr Connect $\mathbf{6}$, $667-675$.

56. Basatemur E \& Sutcliffe A (2015) Incidence of hypocalcemic seizures due to vitamin D deficiency in children in the United Kingdom and Ireland. J Clin Endocrinol Metab 100, E91-E95.

57. Gross ML, Tenenbein MN \& Sellers EA (2013) Severe vitamin D deficiency in 6 Canadian First Nation formula-fed infants. Int $J$ Circumpolar Health 72, 20244.

58. WHO \& FAO (Food and Agricultural Organization of the United Nations) (2006) Guidelines on Food Fortification with Micronutrients. https://www.who.int/nutrition/publications/ micronutrients/9241594012/en/ (accessed December 2019).

59. Black LJ, Seamans KM, Cashman KD, et al. (2012) An updated systematic review and meta-analysis of the efficacy of vitamin D food fortification. J Nutr 142, 1102-1108.

60. Kiely M \& Black LJ (2012) Dietary strategies to maintain adequacy of circulating 25-Hydroxyvitamin D concentrations. Scand J Clin Lab Invest 243, 14-23.

61. Willett W, Rockstrom J, Loken B, et al. (2019) Food in the Anthropocene: the EAT-Lancet Commission on healthy diets from sustainable food systems. Lancet 393, 447-492.

62. Pilz S, Marz W, Cashman K, et al. (2018) Rationale and plan for vitamin $\mathrm{D}$ food fortification: a review and guidance paper. Front Endocrinol 9, 1-16.

63. Cashman KD, Kiely M, Seamans KM, et al. (2016) Effect of ultraviolet light-exposed mushrooms on vitamin D status: liquid chromatography-tandem mass spectrometry reanalysis of biobanked sera from a randomized controlled trial and a systematic review plus meta-analysis. J Nutr 146, 565-575.

64. Hayes A, Duffy S, O'Grady M, et al. (2016) Vitamin D-enhanced eggs are protective of wintertime serum 25-hydroxyvitamin D in a randomized controlled trial of adults. Am J Clin Nutr 104, 629-637.

65. Manios Y, Moschonis G, Mavrogianni C, et al. (2017) Reducedfat gouda-type cheese enriched with vitamin $\mathrm{D}_{3}$ effectively prevents vitamin D deficiency during winter months in postmenopausal women in Greece. Eur J Nutr 56, 2367-2377.

66. Itkonen ST, Skaffari E, Saaristo P, et al. (2016) Effects of vitamin $\mathrm{D}_{2}$-fortified bread $v$. supplementation with vitamin $\mathrm{D}_{2}$ or $\mathrm{D}_{3}$ on serum 25-hydroxyvitamin D metabolites: an 8-week randomised-controlled trial in young adult Finnish women. $\mathrm{Br} J$ Nutr 115, 1232-1239.

67. Natri AM, Salo P, Vikstedt T, et al. (2006) Bread fortified with cholecalciferol increases the serum 25-hydroxyvitamin D concentration in women as effectively as a cholecalciferol supplement. J Nutr 136, 123-127.

68. Cashman KD, Kazantzidis A, Webb AR, et al. (2015) an integrated predictive model of population serum 25-hydroxyvitamin $\mathrm{d}$ for application in strategy development for vitamin D deficiency prevention. J Nutr 145, 2419-2425.

69. Grønborg IM, Tetens I, Christensen T, et al. (2019) Vitamin Dfortified foods improve wintertime vitamin D status in women of Danish and Pakistani origin living in Denmark: a randomized controlled trial. Eur J Nutr. 59, 741-753.

70. Peters DH, Tran NT \& Adam T (2013) Implementation Research in Health: a Practical Guide. Alliance for Health Policy and Systems 
Research, World Health Organization. https://www.who.int/ alliance-hpsr/resources/implementationresearchguide/en/ (accessed December 2019)

71. Jaaskelainen T, Itkonen ST, Lundqvist A, et al. (2017) The positive impact of general vitamin $\mathrm{D}$ food fortification policy on vitamin $\mathrm{D}$ status in a representative adult Finnish population: evidence from an 11-year follow-up based on standardized 25-hydroxyvitamin D data. Am J Clin Nutr 105, 1512-1520.

72. Browning LC \& Cowieson AJ (2014) Vitamin D fortification of eggs for human health. J Sci Food Agric 94, 1389-1396.

73. Cashman KD, Seamans KM, Lucey AJ, et al. (2012) Relative effectiveness of oral 25-hydroxyvitamin $\mathrm{D}_{3}$ and vitamin $\mathrm{D}_{3}$ in raising wintertime serum 25 -hydroxyvitamin $\mathrm{D}$ in older adults. Am J Clin Nutr 95, 1350-1356.

74. PHE (2019) McCance and Widdowson's The Composition of Foods Integrated Dataset (CoFID). PHE Publications. https:// www.gov.uk/government/publications/composition-of-foodsintegrated-dataset-cofid (accessed June 2020).

75. Allen RE, Dangour AD, Tedstone AE, et al. (2015) Does fortification of staple foods improve vitamin D intakes and status of groups at risk of deficiency? A United Kingdom modeling study. Am J Clin Nutr 102, 338-344.

76. EFSA (European Food Safety Authority) Panel on Dietetic Products N \& Allergies (2012) Scientific opinion on the tolerable upper intake level of vitamin D: EFSA panel on Dietetic Products, Nutrition and Allergies (NDA). EFSA J 10, 2813.

77. Tripkovic L, Lambert H, Hart K, et al. (2012) Comparison of vitamin $D_{2}$ and vitamin $D_{3}$ supplementation in raising serum 25-hydroxyvitamin D status: a systematic review and metaanalysis. Am J Clin Nutr 95, 1357-1364.

78. Tripkovic L, Wilson LR, Hart K, et al. (2017) Daily supplementation with 15 mug vitamin $\mathrm{D}_{2}$ compared with vitamin $\mathrm{D}_{3}$ to increase wintertime 25-hydroxyvitamin D status in healthy South Asian and white European women: a 12-week randomized, placebocontrolled food-fortification trial. Am J Clin Nutr 106, 481-490.

79. Hammami MM, Abuhdeeb K, Hammami S, et al. (2019) Vitamin- $\mathrm{D}_{2}$ treatment-associated decrease in $25(\mathrm{OH}) \mathrm{D}_{3}$ level is a reciprocal phenomenon: a randomized controlled trial. BMC Endocr Disord 19, 8.

80. Durrant L, Bucca G, Heskith A, et al. (2021) Vitamins D2 and D3 have overlapping but different effects on human gene expression revealed through analysis of blood transcriptomes in a randomised double-blind placebo-controlled food-fortification trial. medRxiv 12, 20247700

81. Todd JJ, McSorley EM, Pourshahidi LK, et al. (2016) Vitamin $\mathrm{D}_{3}$ supplementation in healthy adults: a comparison between capsule and oral spray solution as a method of delivery in a wintertime, randomised, open-label, cross-over study. Br J Nutr $\mathbf{1 1 6}$, 1402-1408.

82. Satia MC, Mukim AG, Tibrewala KD, et al. (2015) A randomized two way cross over study for comparison of absorption of vitamin $\mathrm{D}_{3}$ buccal spray and soft gelatin capsule formulation in healthy subjects and in patients with intestinal malabsorption. Nutr J 14, 114

83. Menzies IS, Zuckerman MJ, Nukajam WS, et al. (1999) Geography of intestinal permeability and absorption. Gut $\mathbf{4 4}$, 483-489.

84. Uitterlinden AG, Fang Y, Van Meurs JB, et al. (2004) Genetics and biology of vitamin D receptor polymorphisms. Gene $\mathbf{3 3 8}$, $143-156$.

85. Todd JJ, McSorley EM, Pourshahidi LK, et al. (2017) Vitamin $\mathrm{D}_{3}$ supplementation using an oral spray solution resolves deficiency but has no effect on VO2 max in Gaelic footballers: results from a randomised, double-blind, placebo-controlled trial. Eur J Nutr 56, 1577-1587.

86. EFSA (European Food Safety Authority) Panel on Dietetic Products N \& Allergies (2014) Scientific Opinion on the safety of vitamin D-enriched UV-treated baker's yeast. EFSAJ 12, 3520.

87. Bromage S, Gonchigsumlaa E, Traeger M, et al. (2019) Awareness and Attitudes Regarding Industrial Food Fortification in Mongolia and Harbin. Nutrients 11, 201.

88. Cashman KD, Ritz C, Kiely M, et al. (2017) Improved dietary guidelines for vitamin D: application of individual participant data (IPD)-level meta-regression analyses. Nutrients 9, E469. 